DOEIER-0021/1

19. 2246

Vol. 1 of 2

\title{
Preliminary Environmental Assessment for the Satellite Power System (SPS)
}

Volume 1

Executive Summary

October 1978

\section{U.S. Department of Energy}

Office of Energy Research

Satellite Power System Project Office

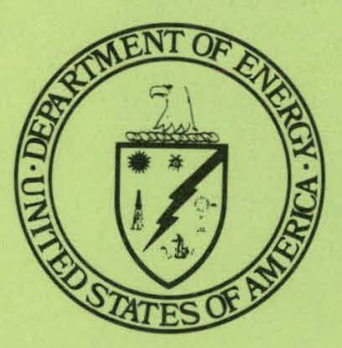

DOE/NASA

SATELLITE POWER SYSTEM

Concept Development and

Evaluation Program

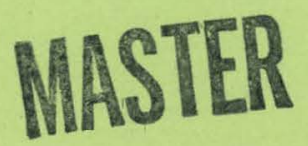




\section{DISCLAIMER}

This report was prepared as an account of work sponsored by an agency of the United States Government. Neither the United States Government nor any agency Thereof, nor any of their employees, makes any warranty, express or implied, or assumes any legal liability or responsibility for the accuracy, completeness, or usefulness of any information, apparatus, product, or process disclosed, or represents that its use would not infringe privately owned rights. Reference herein to any specific commercial product, process, or service by trade name, trademark, manufacturer, or otherwise does not necessarily constitute or imply its endorsement, recommendation, or favoring by the United States Government or any agency thereof. The views and opinions of authors expressed herein do not necessarily state or reflect those of the United States Government or any agency thereof. 


\section{DISCLAIMER}

Portions of this document may be illegible in electronic image products. Images are produced from the best available original document. 
Available from:

National Technical Information Service (NTIS)

U.S. Department of Commerce

5285 Port Royal Road

Springfield, Virginia 22161

Price: Printed copy: $\$ 5.25$

Microfiche: $\$ 3.00$ 
DOE/ER-0021/1

Vol. 1 of 2

- Disț. Category UC-11, 41, 60, 63,

$63 \mathrm{a}, \mathrm{b}, \mathrm{c}, \mathrm{e}, 64,66 \mathrm{e}, 95 \mathrm{f}, 97 \mathrm{c}$

\section{Preliminary Environmental Assessment for the Satellite Power System (SPS)}

Volume 1
Executive Summary

October 1978

\section{U.S. Department of Energy \\ Office of Energy Research}

Satellite Power System Project Office Washington, D.C. 20545

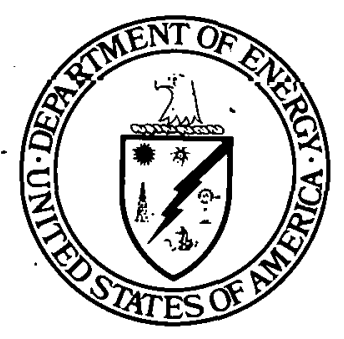

\section{DOE/NASA}

SATELLITE POWER SYSTEM

Concept Development and

Evaluation Program

\footnotetext{
Evaluation Program
}

This report was prepared as an account of work sponsored by the United States Govemment. Neither the United States nor the United States Department of

Energy, nor any of their employees, nor any of their

contractors, subcontractors, or their employees, makes

any warranty, express or implied, or assumes any legal

liabiliy or responsility ior the aceury, completents

(1)

or usefulness of any inform then, appartus. product or

process disclosed, or represents that its use would not
infringe privately owned nigh ts. 


\section{THIS PAGE}

\section{WAS INTENTIONALLY LEFT BLANK}


FOREWORD

The Department of Energy is considering several options for generating electrical power to meet future energy needs. The satellite power system (SPS), one of these options, would collect solar energy through a system of orbiting satellites, convert the energy to microwaves, and transmit the microwave energy via extremely directive transmitting antennas to large receiving antennas (rectennas) located on the earth. Present conceptual designs provide for microwave transmission at a frequency of 2.45 gigahertz and generation of 5 to 10 gigawatts-electric at each rectenna.

The impact of the SPS microwave transmission on the environment, as well as impacts related to other elements of the total satellite power system, are being determined by several research efforts funded by the Department of Energy. The goal of these programs is to advance the state of knowledge by the year 1980 to the point where the probability and severity of SPS impacts can be assessed. This two-volume document presents a preliminary evaluation of SPS environmental impacts and recommends impact-related research. More detailed and extensive assessments will be made of effects on the health and safety of the public and occupationally involved personnel, ecosystems, the upper and lower atmosphere, and communications systems.

If the 1980 assessments indicate that the impacts are acceptable or that feasible mitigating strategies can be implemented, and if other related assessments (the impact on society and a competitive comparison of the SPS with other energy alternatives) are favorable, a decision may be made to develop SPS-related technologies.

\section{CONTRIBUTORS}
S.L. Halverson
Argonne National Laboratory, Director, Envi i viunent al As sco ement
D.M. Rote
Argonne National Laboratory, Director, Task III
J.L. Lee
Argonne National Laboratory
K.L. Brubaker
Argonne National Laboratory
R.R. Cirillo
Argonne National Laboratory
S.W. Ballou
Argonne National Laboratory
S.D. Parris
Argonne National Laboratory
D.F. Cahill
J. Allis
U.S. Environmental Protection Agency, Director, Task I
U.S. Environmental Protection Agency
K. Davis
C.M. Rush
E. Morrison
W. Grant
Battelle Pacific Northwest Laboratories, Director, Task IV
M. White
Institute for Telecommunication Sciences, Director, Task IV
Institute for Telecommunication Sciences
Institute for Telecommunication Sciences
Lawrence Berkeley Laboratory, Director, Task II 


\section{THIS PAGE}

\section{WAS INTENTIONALLY LEFT BLANK}


PURPOSE . . . . . . . . . . . . . . . . . . . . . . . . . 1

INTRODUCTION. . . . . . . . . . . . . . . . . . . . . 1

1 MICROWAVE HEALTH AND ECOLOGICAL EFFECTS. . . . . . . . . . . . . . 3

2 OTHER EFFECTS ON HEALTH AND THE ENVIRONMENT. . . . . . . . . . . . 9

2.1 Effects on the Public . . . . . . . . . . . . . . . . . 10

2.1.1 Impacts of Conventional Processes. . . . . . . . . . 10

2.1.2 Unconventional Effects............... 13

2.2 Effects on Terrestrial Workers. . . . . . . . . . . . . . 18

2.2.1 Impacts of Conventional Processes. . . . . . . . . . . 19

2.2.2 Unconventional Effects............... 20

2.3 Effects on Space Workers. . . . . . . . . . . . . . . 20

2.3.1 Weightlessness . . ................ . 21

2.3.2 Life Support . . . . . . . . . . . . . . . 22

2.3.3 Radiation. . . . . . . . . . . . . . . . . 22

2.4 Effects on the Environment. . . . . . . . . . . . . 23

3 EFFECTS ON THE ATMOSPHERE. . . . . . . . . . . . . . . . . . . 25

3.1 Microwave and Rectenna-Related Effects in the Troposphere . . 28

3.2 Nonmicrowave Atmospheric Effects above $60 \mathrm{~km}$. . . . . . . . . 30

3.3 Nonmicrowave Effects in the Stratosphere/Mesosphere . . . . . 32

4 EFFECTS ON COMMUNICATIONS. . . . . . . . . . . . . . . . . . 33

4.1 Electromagnetic Compatibility . . . . . . . . . . . . . 33

4.1.1 Methodology. . . . . . . . . . . . . . . . 33

4.1.2 State of Knowledge . . . . . . . . . . . . 35

4.1.3 Preliminary Assessment . . . . . . . . . . . . . . . 36

4.1.4 Conclusions and Recommendations. . . . . . . . . . . . 42

4.2 Ionospheric Heating and Vehicle Effluent Effects. . . . . . . 44

\section{LIST OF FIGURES}

1.1 Exposure of Humans and Ecosystems to Microwave Energy from the Satellite Power System . . . . . . . . . . . . . . . . . . 4

1.2 Possible Human Health Effects from SPS Microwaves. . . . . . . 5

1.3 Possible Ecological Effecte from SPS Microwaves. . . . . . . . . 6

2.1 Nonmicrowave Effects of SPS on the Public. . . . . . . . . . . . 10

2.2 SPS Material Requirements. ................... 11

2.3 SPS Environmental Impacts. . . . . . . . . . . . . . . 12

2.4 Recommended Maximum Launch-Related Air Pollutant Concentrations. 15

2.5 Maximum Allowable Concentrations of Propellants in Water . . . 16 
2.6 Launch Noise Profile . . . . . . . . . . . . . . . . 17

2.7 Nonmicrowave Effects of SPS on Terrestrial Workers . . . . . . 18

2.8 Occupational Injury and Illness from Conventional SPS Causes : . 19

2.9 Nonmicrowave Effects of SPS on Space Workers . . . . . . . . . 21

3.1 Regions of the Atmosphere. . . . . . . . . . . . . . . 26

3.2 Summary of Some Potential Atmospheric Effects Caused by Rocket Exhaust . . . . . . . . . . . . . . . . . . . . . 27

3.3 Climatological and Heating Effects of the Microwave Power Transmission System in the Lower Atmosphere. . . . . . . . . . . . 79

4.1 SPS Radio Frequency and Electromagnetic Interference . . . . . . 33

4.2 Rasic EMC Analyses Elements. . . . . . . . . . . . . . . . . . 34

4.3 SPS Transmitting Antenna Yattern . . . . . . . . . . . . . . 36

4.4 Effect of SPS Microwave Transmission on the Ionosphere and Telecommunication System . . . . . . . . . . . . . . . . . 44

\section{LIST OF TABLES}

4.1 Selected Site Distances from Mojave Rectenna . . . . . . . . . . 37

4.2 Scatter Power Densities - Average Rain Conditions. . . . . . . . 39

4.3 Induced-Functional-Degradation Summary - Mojave Area . . . . . . 41 
PURPOSE

The purpose of Volume I of this document is to provide an abstract of the more technically explicit information contained in Volume II concerning the preliminary assessment of the 1mpact of the Satellite Power System (SPS) on the environment, for the edification of the interested layman.

\section{INTRODUCTION}

This preliminary environmental assessment of the Satelite Power System reference design is of necessity based on existing research and analytical results. Some additional research has either been started or is contemplated, but it is still too early for this work to be a factor in the present evaluation. Where the data base is now inadequate, it has been necessary to elther make preliminary assessments with appropriate caveats or to defer evaluation pending further development of the state of the art. 
THIS PAGE

WAS INTENTIONALLY

LEFT BLANK 


\section{MICROWAVE HEALTH AND ECOLOGICAL EFFECTS}

The microwave power transmission system for satellite power systems will expose the general population and the environment to low levels of microwave radiation. In addition, there will be a potential for high levels of exposure under certain conditions, e.g., for birds flying over a rectenna site, and occupational exposure of workers both at the rectenna site and at the satellite generating facility. A representation of the exposure of the population and the ecosystem is presented in Fig. 1.1.

In light of these facts, the health and ecological effects of such exposure to SPS microwave radiation must be determined. The international literature in this area consists of roughly 5000 citations. The majority of these publications originate from research in the Soviet Union and other East European countries. Very basic differences in experimental design, statistical analyses, and technical reporting between U.S. and Soviet scientists have limited the value and applicability of this potential resource in the judgment of most Western investigators. Of the remaining reports, relatively few are concerned with the health effects of continuous wave $2.45 \mathrm{GHz}$ radiation and almost none with the ecological effects. Although a data base does exist for the SPS-specific frequency, it is incomplete, often contradictory, and not entirely pertinent to the environmental conditions projected to be associated with SPS. The available base consists mainly of limited observations on the consequences of short-term, high-exposure-level health effects in animals. While the data on the effects on animals have a qualitative value, Lhe essential information needs are for data on the effects on human health of continuous or chronic exposure at very low levels. Figure 1.2 diagrams the types of effects that may be harmful to human health.

In the SPS microwave health and ecology program two types of studies must be combined to arrive at an assessment of impacts. One type, which we call prospective, will be directed toward research areas where no data exist and which pose serious questions about the feasibility of using a microwave transmission beam for SPS. Principal among these are the effects of continuous, low-level exposure on humans and short-term high-level exposures on airborne biota. Long-term studies using experimental animals will be the primary determinants in answering some of these questions, but much 


\section{Solar Power Satellite}

FUELED BY THE SUN'S RAYS.

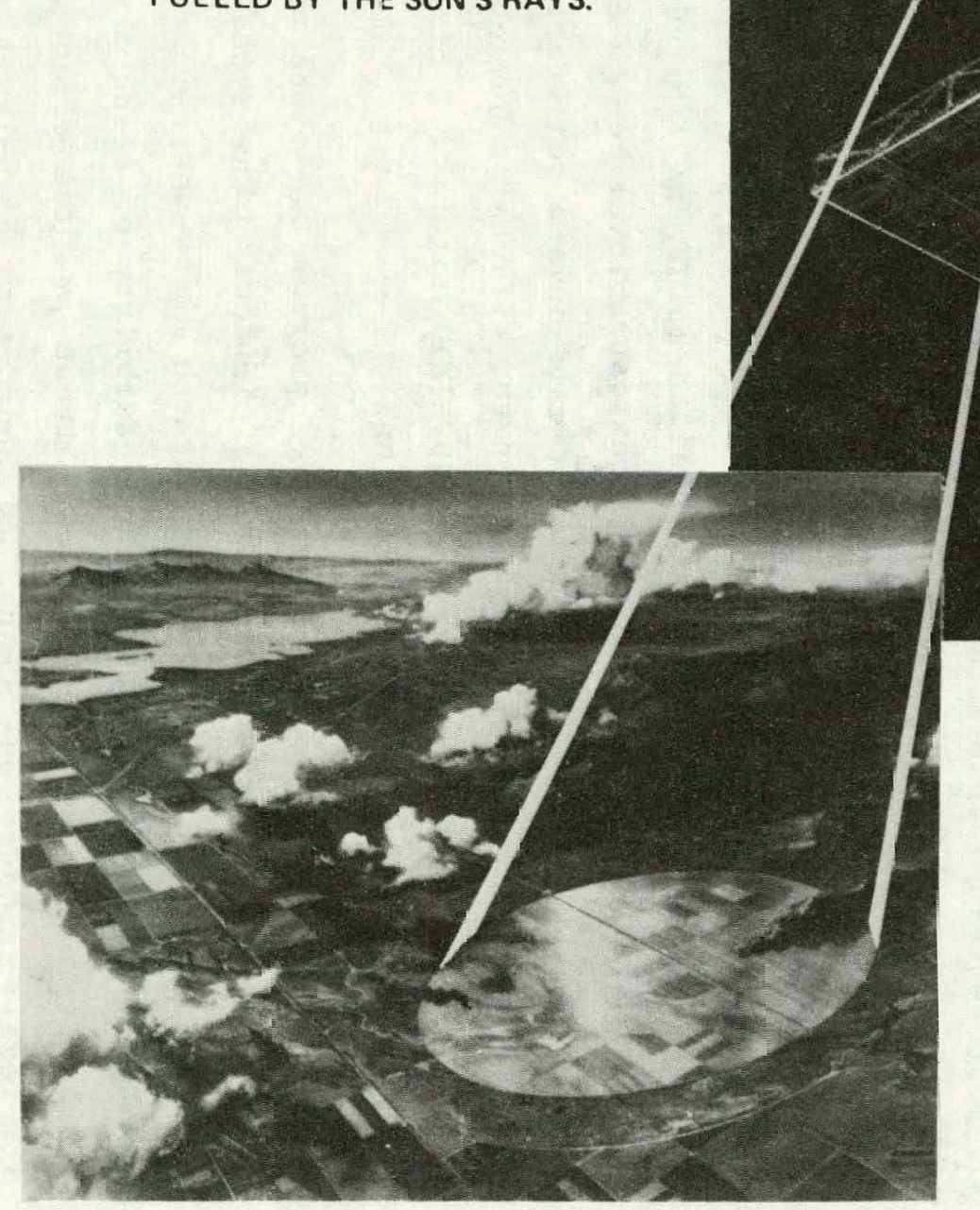

\section{Earth Receiver}

PROVIDER OF ELECTRICITY FOR A NILLION HOMES

OR THOUSANDS OF SMALL INDUSTF AL PLANTS 


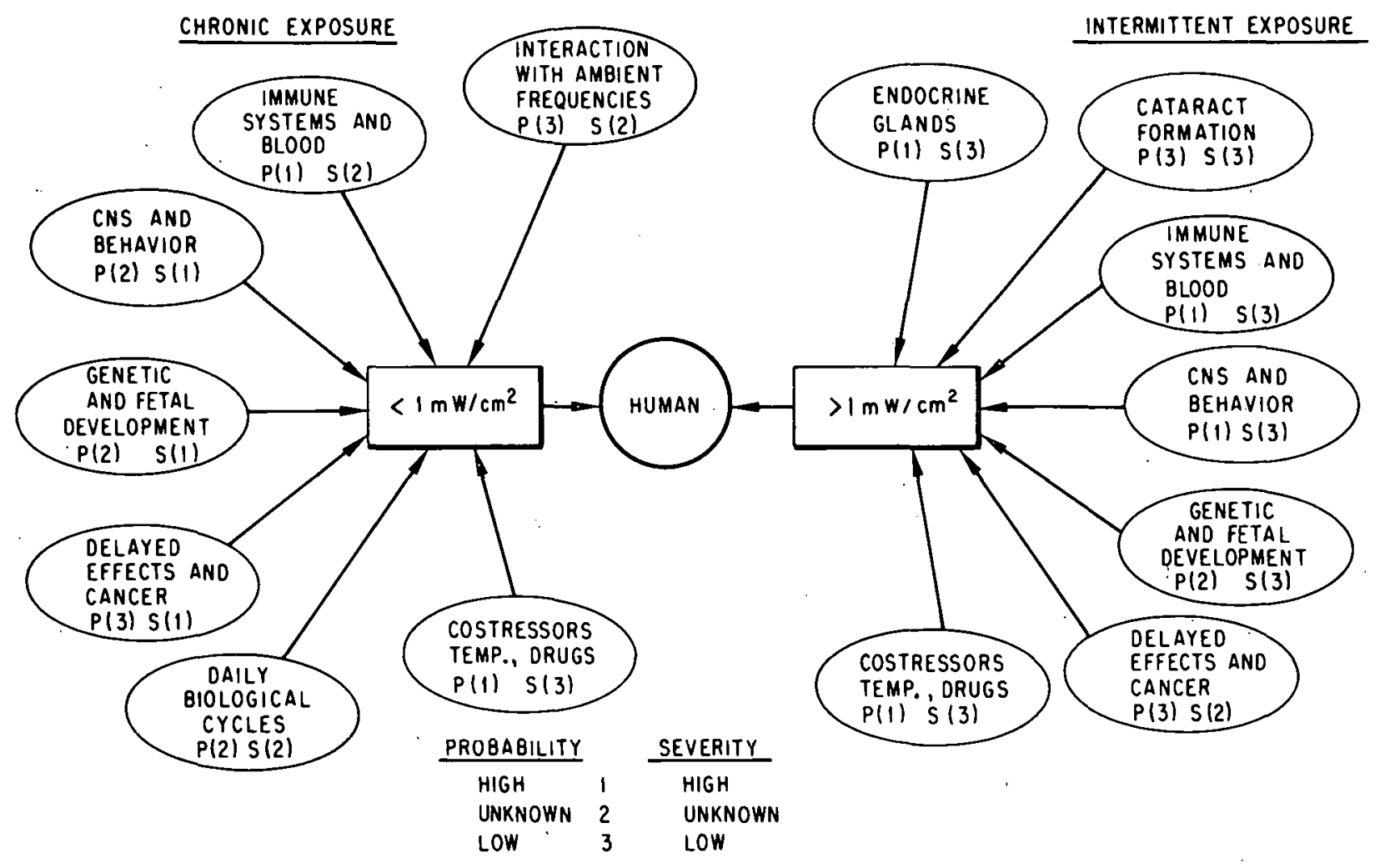

Fig. 1.2. Possible Human Health Effects from SPS Microwaves

of this work will not be within the scope of the FY 1978-80 program plan. However, short-term prospective studies will address several questions that can be answered in this time span, particularly those concerning overt effects on alrborne biota.

The other type of study, which we call retrospective, will address effects reported in the literature. A major effort must be made to validate the apparently credible, published reports of potential adverse health effects of the $2.45 \mathrm{GHz}$ radiation transmitted from the satellite to the rectenna. In addition, effects reported at certain other frequencies should be investigated to determine whether they also occur at $2.45 \mathrm{GHz}$. The intent behind the retrospective studies is to evaluate objectively the effects reported at such frequency and power densities as are appropriate to the SPS program. The information developed from this work will be used in the design of the longterm experiments to be conducted after 1980 .

Only rarely has microwave-effects research been performed that has direct ccological implicatinns and in no study has the impact of microwaves on an entire ecosystem been attempted. Nevertheless, in a cursory review of the 
literature in this area, several reports that may have a bearing on the SPS program have been identified. These studies imply that, at least at very high-level exposures, some plants have increased susceptibility to drought and decreased productivity, and avian species may be subject to increased lethality, decreased reproductive success, and alteration in normal behavior. Data do not exist on the ecological effects of continuous, low-level exposures expected to be associated with SPS. Figure 1.3 illustrates the kinds of efects that may present ecological hazards.

As a first step, a comprehensive review and critical interpretation of the literature on the ecological effects of microwaves will be conducted. A computer-retrievable information system will be developed that will allow a systematic analysis of the information available. From the results of this analysis, ecological research protocols will he formulated that will provide the key information for evaluating effects in the critical ecological systems.

$3 \mathbf{A}$
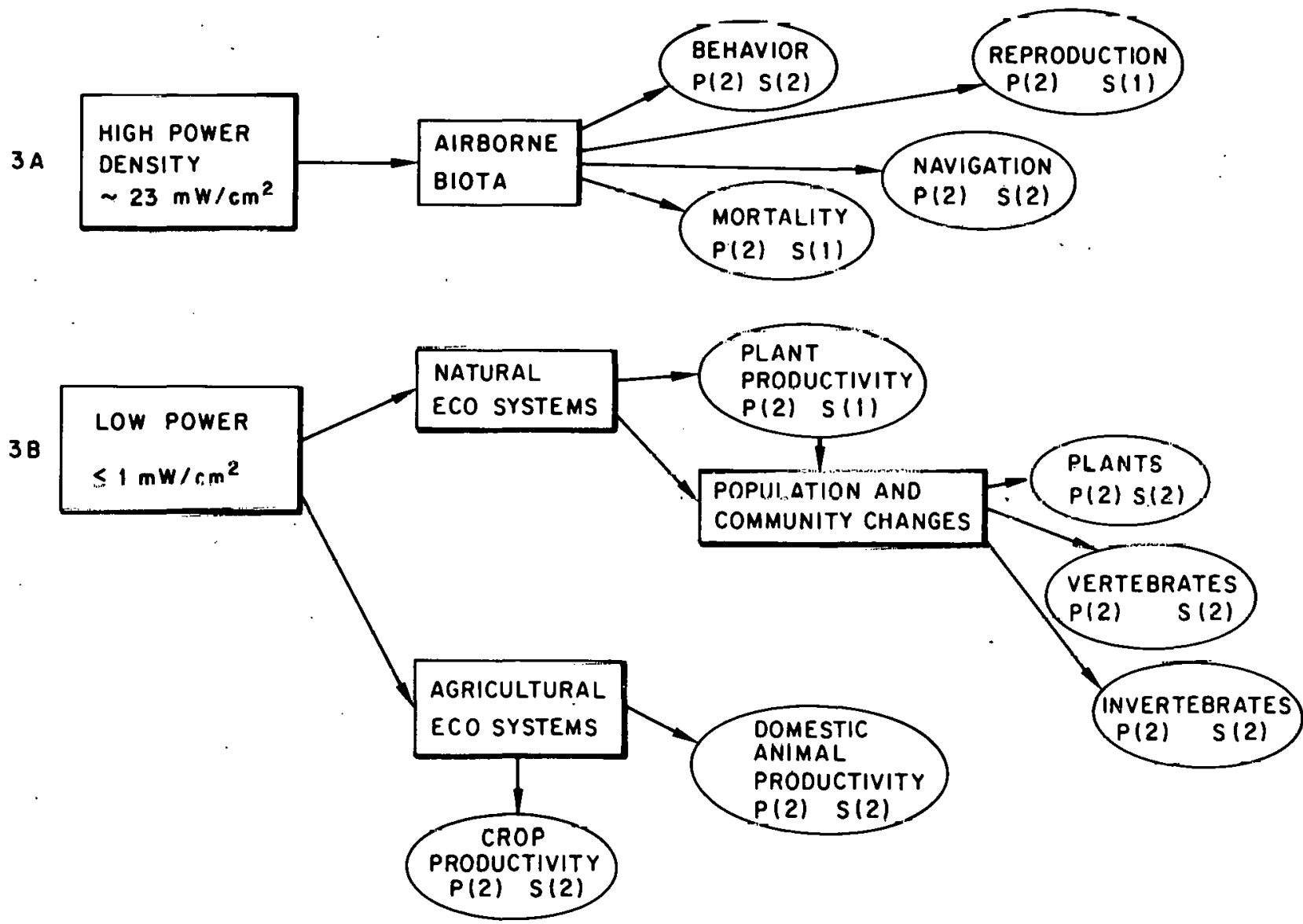

Fig. 1.3. Possible Ecological Effects from SPS Microwaves 
Particular emphasis will be placed on the relationship between rectenna operations and ecology. For a full understanding of the effects of long-term exposure on ecosystems, it will be necessary to develop an experiment in which an entire ecological park of extensive area is exposed.

During the next one to two years (FY 1979 and 1980), we can expect to be able to evaluate the pertinence of health effects noted in the literature (retrospective studies) to satellite power systems transmitting $2.45 \mathrm{GHz}$ microwaves. We can also expect to see results from some short-term studies such as those on lethality thresholds for birds and other airborne biota. Finally, the literature review and computer-retrievable information system will be developed and used to formulate the ecological experiments to be accomplished after FY 1980 . 
THIS PAGE

\section{WAS INTENTIONALLY LEFT BLANK}


2 OTHER EFFECTS ON HEALTH AND THE ENVIRONMENT

In addition to the impacts of microwaves, a number of other health and safety effects can be anticipated from the deployment of an SPS. These result from:

- Mining of raw materials,

- Construction of terrestrial facilities,

- Processing and fabrication of finished materials,

- Transport. of materials and equipment,

- Ground station operation,

- Space vehicle launch and recovery

- Orbital transfer of material and personnel,

- Construction of SPS arrays, and

- Operation of arrays.

These activities will produce various effects on the general public, terrestrial workers, space workers, and the environment. All of the possible impacts that a satellite power system may generate must be considered in order to assess its acceptability and develop strategies for minimizing or eliminating undesirable conditions.

It must be recognized that the activities indicated above produce two distinctly different types of effects. First, some of the activities are conventional processes (e.g., mining, construction, processing, transport), not unique to satellite power systems. The impacts they produce are common to any use of those processes. For example, the health effects of air pollution generated by steel-making are the same whether that steel is used for automobiles, bridges, power plants, or an SPS. An evaluation of these impacts here is significant only insofar as sps deployment results in a substantial increase in a particular activity and its accompanying effects. Because of the extent of experience with these processes, the effects they produce, and the effectiveness of alternative control strategies, an acceptable assessment can be made of potential SPS impacts.

The second type of effects results from the activities that are unique to SPS deployment (e.g., handling of large quantities of gallium arsenide for solar cells, exposure of construction workers to extended periods of space radiation, etc.). 'The available data are often limited in comprehensiveness, 
detail, or accuracy, making an assessment of potential SPS impacts difficult. In some situations a complete assessment must await additional basic research to establish the nature of the effects.

\subsection{EFFECTS ON THE PUBLIC}

The general public will experience the health and safety effects of SPS deployment through a variety of pathways, as shown in Fig. 2.1.

\subsubsection{Impacts of Conventional Processes}

The conventional processes of mining, construction, manufacturing, and transportation will produce effects through:

- Land disturbancé,

- Air pollution generation,
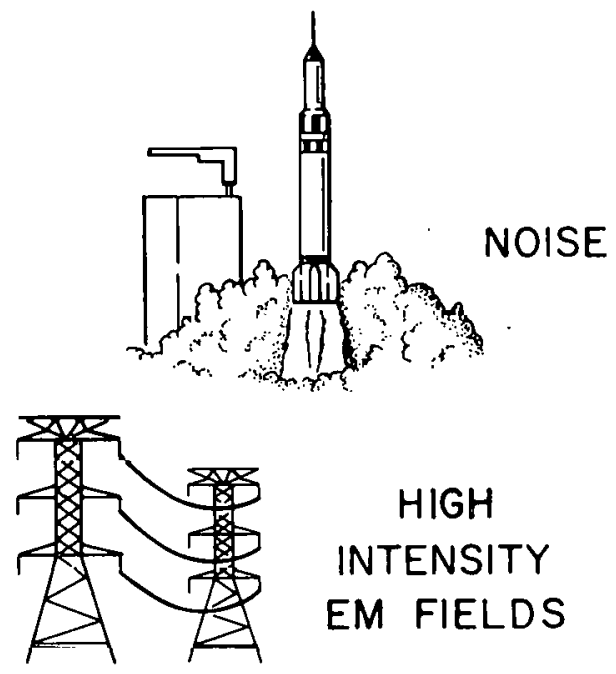

$\mathrm{HIGH}$ INTENSITY EM FIELDS
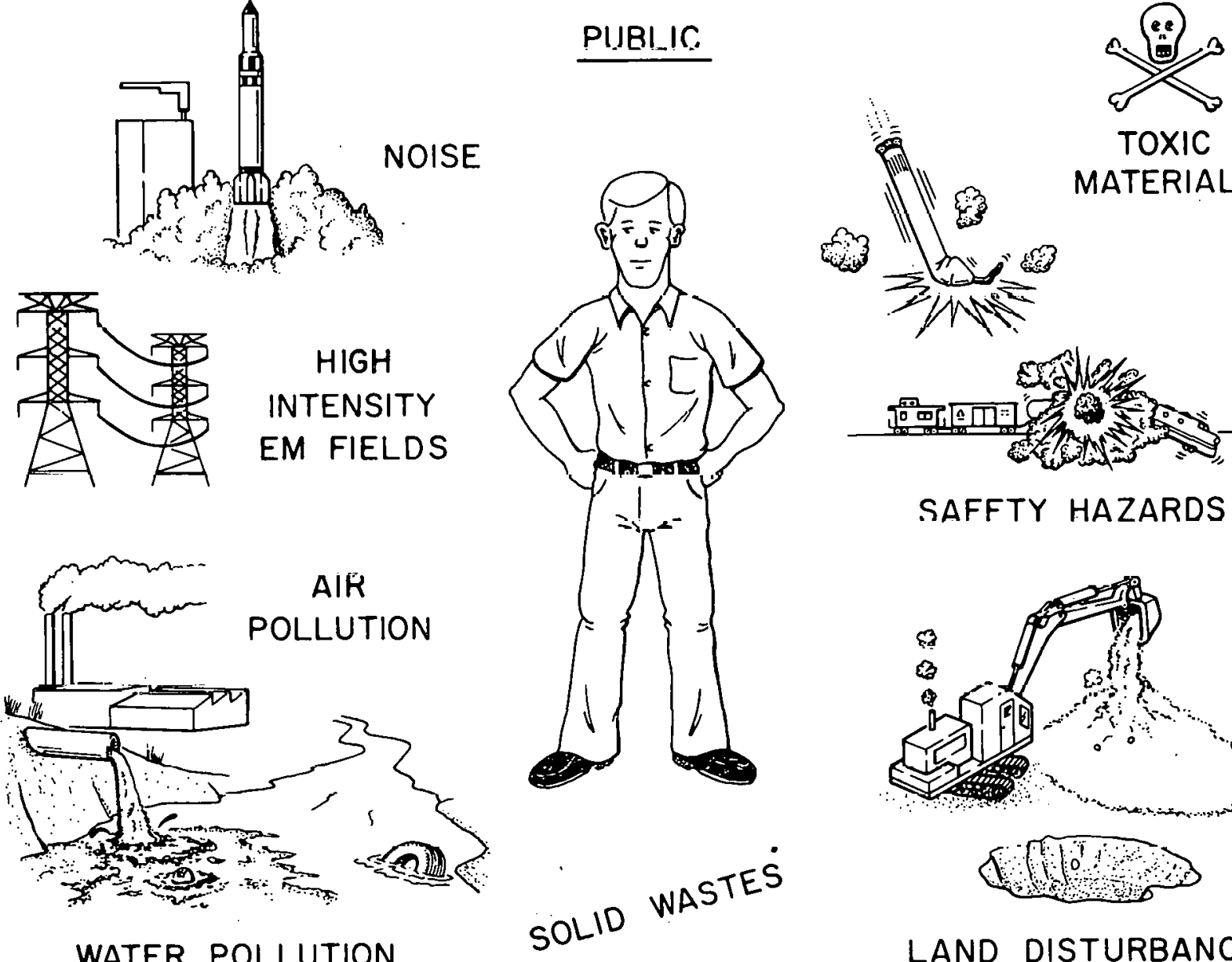

TOXIC MATERIALS

WATER POLLUTION
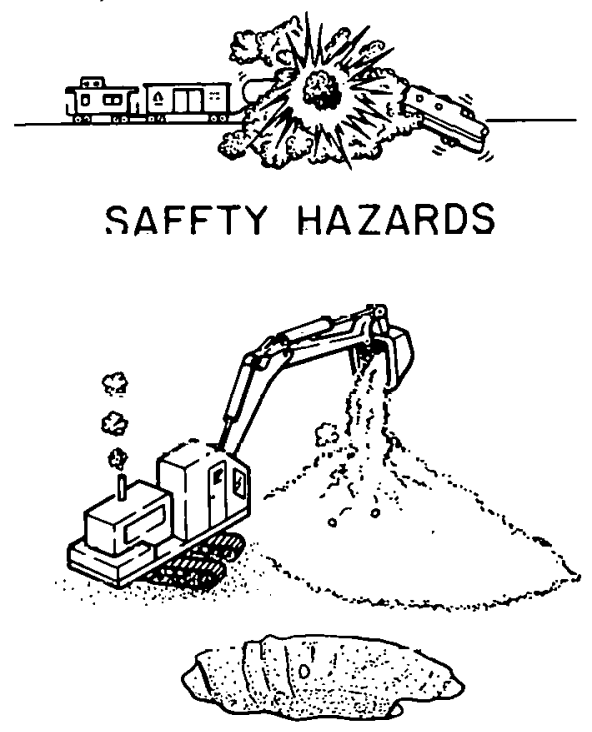

LAND DISTURBANCE

Fig. 2.1. Nonmic rowave Effects of SPS on the Public 
- Water pollution generation, and

- Solid waste generation.

The extent of SPS-related effects can be measured by the increase in activity resulting from SPS requirements. One such measurement is a comparison of the materials requirements of an SPS system and total U.S. production, as given in Fig. 2.2. (Note that the SPS requirements are system totals for a 5-15 year period, while the U.S. production data are for one year.) Some of the materials shown (e.g•, mercury, argon, hydrogen, oxygen) represent a substantial portion of a one-year U.S. production rate. It can be assumed that the air pollution, water pollution, and solid waste generated by SPS requirements for these materials will be a measurable increment over existing levels generated

\section{THE MATERIALS REQUIREMENTS ARE A MEASURE OF INCREASED CONVENTIONAL ACTIVITY}

TOTAL SYSTEM

MATERIALS 0
$\%$ OF U.S. ANNUAL PRODUCTION

$\begin{array}{lllll}10 & 20 \quad 30 \quad 40 \quad 50 \quad 60\end{array}$

$70 \quad 80$

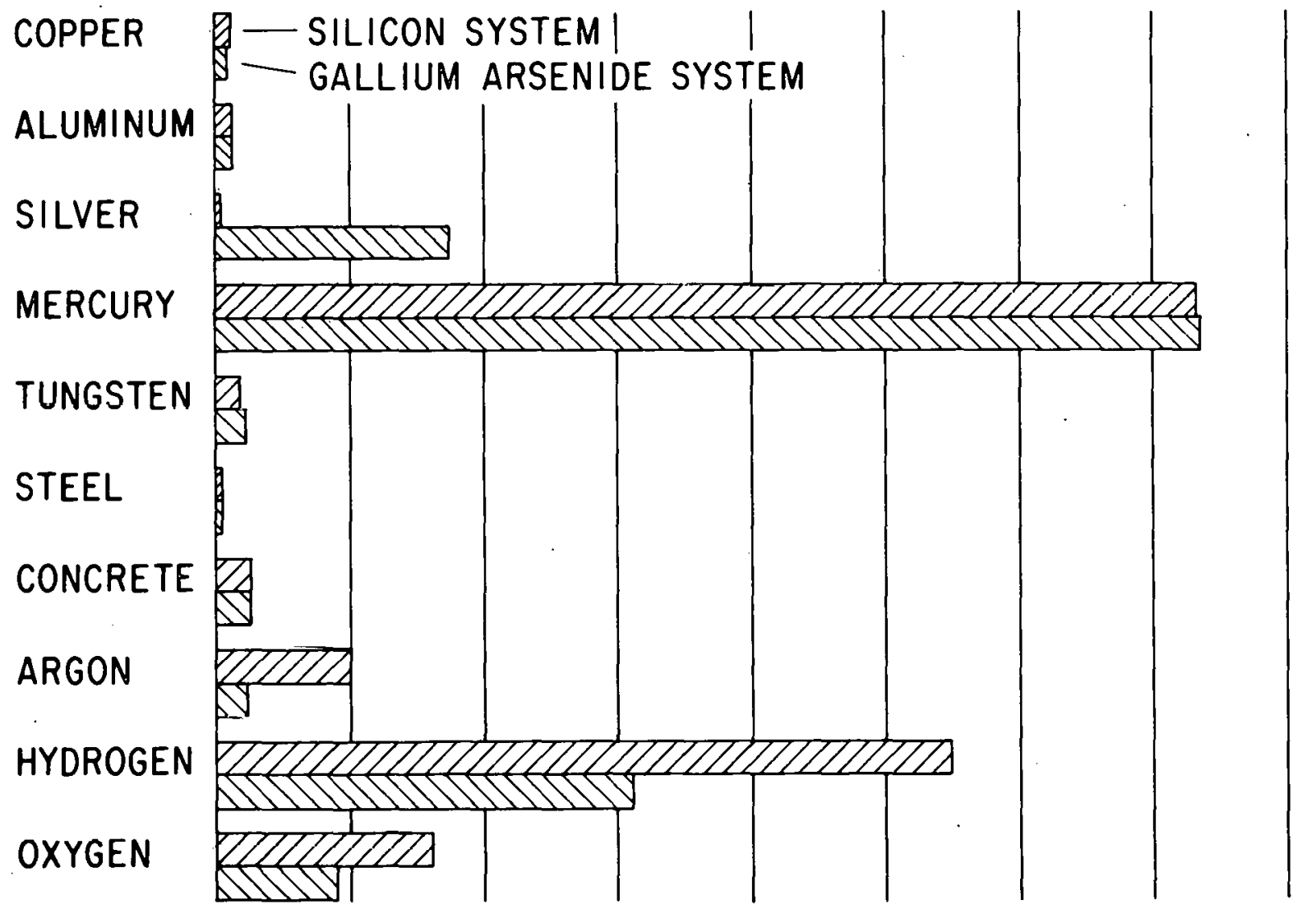

Fig. 2.2. SPS Material Kequirements 
by these processes. The SPS requirements for other materials (e.g., aluminum, concrete) are a small portion of U.S. total annual production, but their impacts can still be large due to the large absolute quantities of materials involved.

An attempt has been made to translate SPS materials requirements into actual pollutant loadings, as shown in Fig. 2.3. (Note that sps system totals, based on an earlier SPS design configuration, are again being compared to U.S. annual totals.) The air pollution, water use, solid waste generation, and land use requirements represent measurahle incremento of a one-year U.S. total, indicating that the effects of SPS deployment will not be negligible.

THE MATERIAL REQUIREMENTS CAN BE TRANSLATED INTO ENVIRONMENTAL LOADINGS

$\square$ SPS SYSTEM TOTAL $\square$ U.S. ANNUAL TOTAL $\begin{array}{lllllll}0 & 10 & 20 & 30 & 80 & 90 & 100\end{array}$

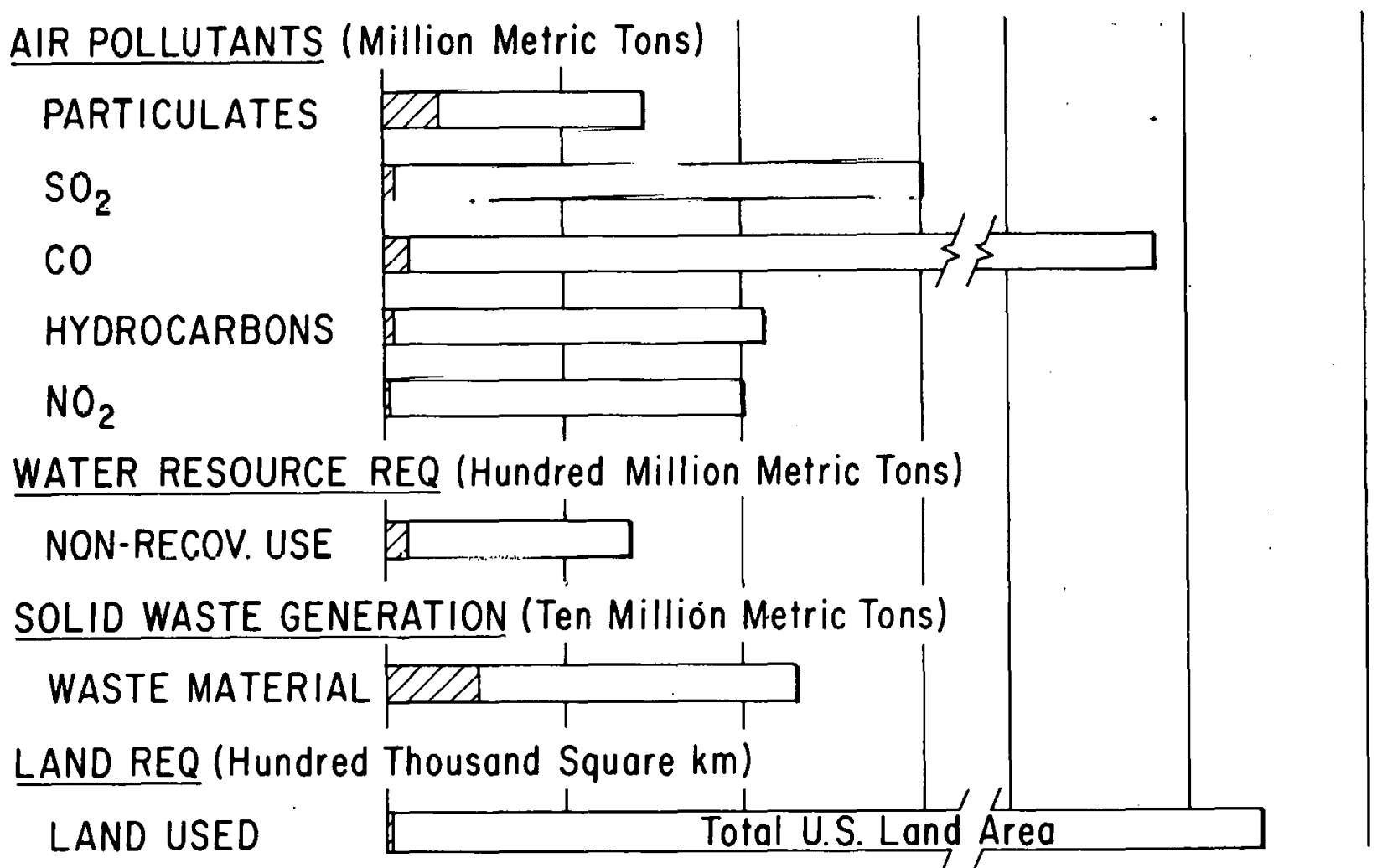

Fig. 2.3. SPS Environmental Impacts 


\subsubsection{Unconventional Effects}

Toxic Materials. To date, no systematic identification of any toxic materials involved in SPS deployment has been made. Until this materials list is developed, the potential public health effects of exposure to these substances cannot be assessed. The continuing environmental assessment will attempt to compile such a list, review the state of knowledge of health effects, quantify the potential for public exposure, and evaluate alternative control measures.

Transport Accidents. A sizable quantity of highly explosive rocket propellants will need to be transported to the launch site in the course of SPS launch operations. The one of most serious concern is liquid hydrogen, which is currently transported by tank truck to launch sites but is under consideration for transport by barge or rail car. Liquid hydrogen spills can ignite immediately or have a delayed igition. Upon immediate ignition a flash occurs that can produce thermal radiation sufficient to cause firstdegree burns and ignite light combustibles, such as paper, some distance away. If immediate ignition does not occur, the cloud of gaseous hydrogen could be dispersed downwind and ignited by some remote spark. However, this possibility is limited by the dilution of the cloud through mixing with the air.

Other explosive and/or highly flammable materials include monomethylhydrazine, hydrazine, and nitrogen tetroxide, used in chemical liquid propellants. These are of more concern because of their high toxicity rather than their flammalility.

Spills of liquid oxygen could also create significant local impacts, notably on ecosystems. The extreme cold is the principal cause of damage.

Although data are available on the results of transportation accidents, they have not been translated into actual health and safety effects, i.e., injury rates. To do so would require an analysis of accident probability and an evaluation of probable transport corridors to determine public exposure hazards. An evaluation of these problems will be included as part of the ongoing assessment. 
Launch and Recovery Air Pollution. The launch activity results in air quality impacts from the exhaust products of the launch vehicle and from the formation at the launch platform and dispersion of a "ground cloud" made up of exhaust gases and cooling waer along with some sand and dust. The ground cloud has the potential for creating direct public exposure to air pollutants because of its low altitude. A mathematical model has been developed to estimate the maximum concentrations of various pollutants in the ground cloud as a result of space shuttle operations. These results are not directly applicable to SPS operations because of the probable use of liquidfueled rockets (versus snlid-fueled for the shuttle) and the significantly larger launch vehicle size. The model has not yet been used for the SPS launch vehicle configuration.

The Committee on Toxicology of the National Academy of Sciences/National Research Council (NAS/NRC) has recommended concentration limits for launch-related air pollutants (see Fig. 2.4) that include a short-term public limit (STPL) designed to avoid respiratory irritation and a public emergency limit (PEL) related to accident conditions that might result in some irritation but with reversible effects.

Test flights and the testing of rocket engines, orbital maneuvering systems, and reaction control systems will also release air pollutants. Examination of the effects of such pollution, as well as further analysis of the ground cloud, will be included in the ongoing assessment.

Launch and Recovery Water Quality Impacts. No assessment has been made of the water quality effects of the launch and recovery of SPS vehicles; however, some information is available for the space shuttle. Potential pollutants enter the water through contamination of the launch pad cooling water with engine exhaust products and removal of ablative insulation from reentry vehicles with high pressure water jets, and possibly through spillage of residual propellant if the launch vehicle is recovered from the ocean. The first two conditions can be controlled by onsite water treatment facilities and would not normally present a public health problem. Suggested maximum allowable concentrations for propellant spills are available and are shown in Fig. 2.5. The ongoing assessment will attempt to determine the ability of the SPS system to control spills to these levels. 


\section{MAXIMUM CONCENTRATION LIMITS ARE AVAILABLE FOR AIR POLLUTANTS}

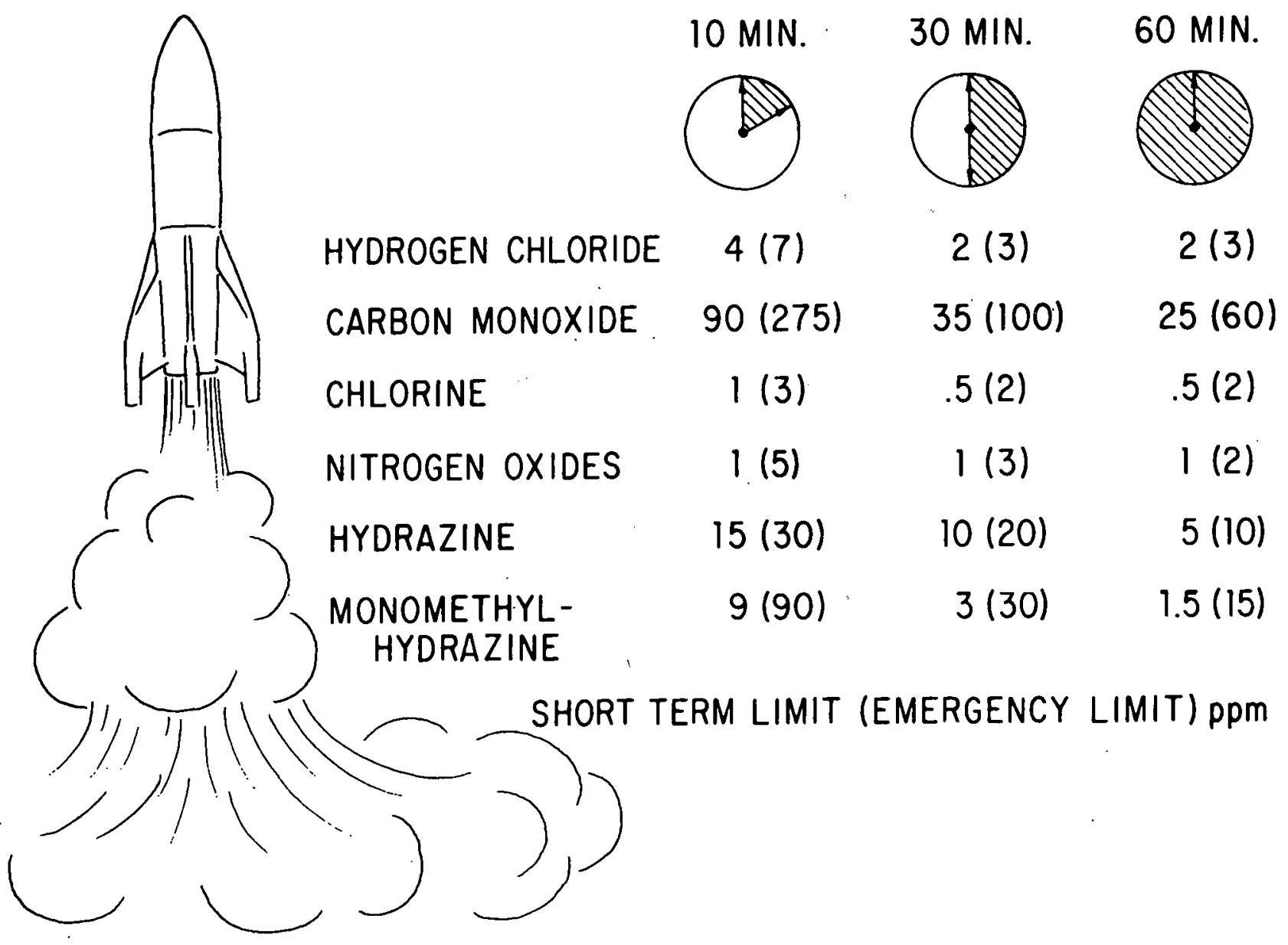

Fig. 2.4. Recommended Maximum Launch-Related Air Pollutant Concentrations

Launeh and Recovery Noise. Noise impact.s from SPS operations will come from the sound level generated by the heavy lift launch vehicle (HLLV) during ascent and from sonic booms created during ascent and reentry. Figure 2.6 shows the sound pressure levels of the HLLV. To assess the impacts of these levels on the public, two conversion steps are necessary. First, the absolute sound pressure must be converted to what is called an A-weighted level to account for the eansitivity of the human ear to different frequencies. Second, the short-term sound pressure levels must be integrated into an overall sound level using weighting factors that account for time of day, frequency of occurrence, and duration of noise level. The U.S. Environmental Protection Agency uses a 24-hour weighted average for its $70 \mathrm{db}(\mathrm{A})$ daytime guideline and its $50 \mathrm{~dB}(\mathrm{~A})$ nighttime guideline. Considering that the overall 


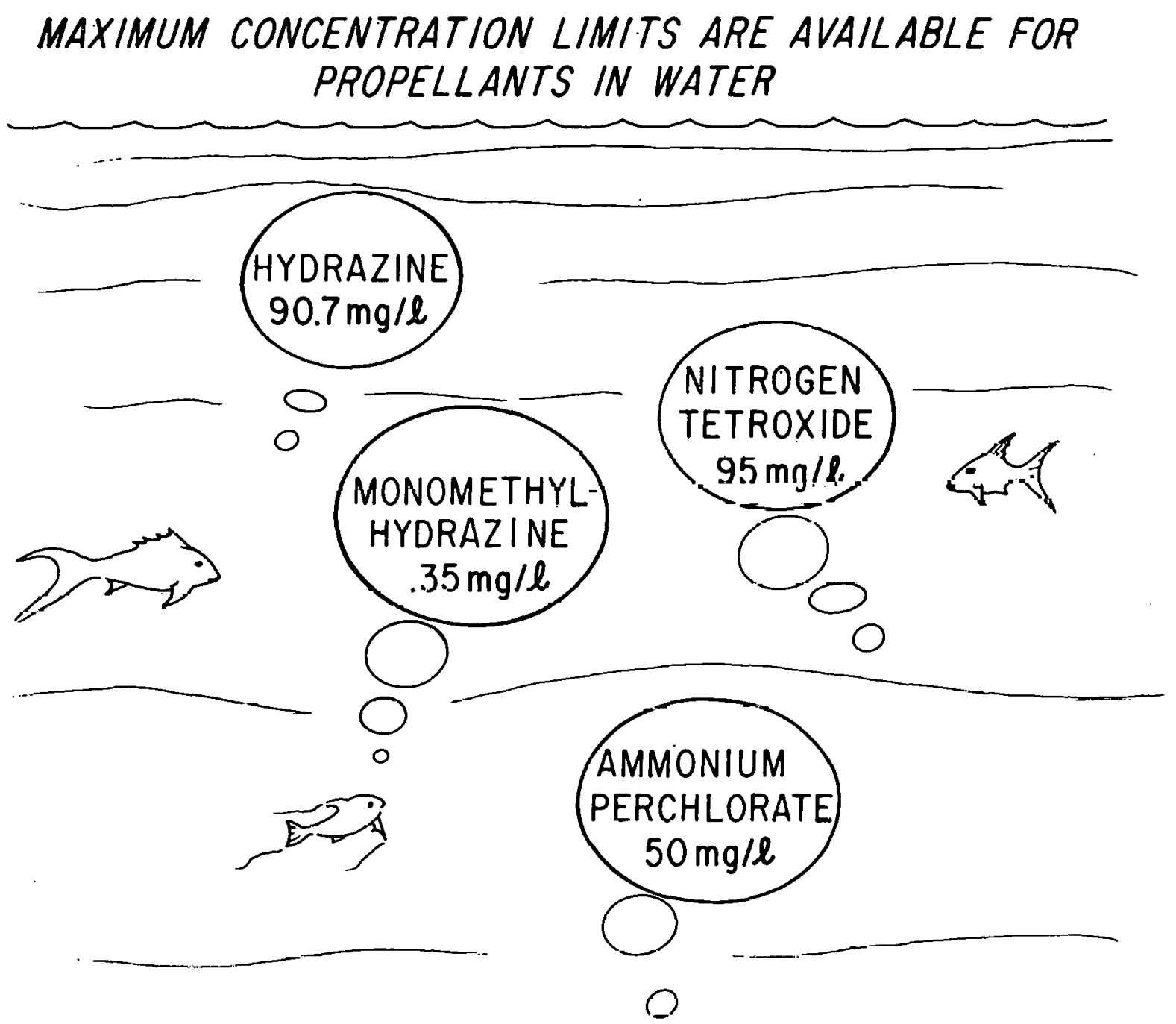

Fig. 2.5. Maximum Allowable Concentrations of Propellants in Water

sound pressure levels of the HLLV are greater than those of the Saturn $V$ used in the Apollo moon program and that there would be several launches per day, it appears that the EPA guidelines may be exceeded by the SPS launching program. More detailed system analysị will be required for verification.

Sonic booms will be caused by the supersonic flight of the space vehicles during ascent and reentry. The impacts of sonic booms come from their abruptness, which startles humans, and from the intensity of the nverpressure, which causes property damage. No information is available on SPS vehicle sonic boom generation; however, considering the large size of the SPS components and the frequency of sonic boom occurrence, it is evident that some 
ACOUSTIC NOISE IMPACTS RESULT PRIMARILY FROM

LAUNCH ACTIVITIES
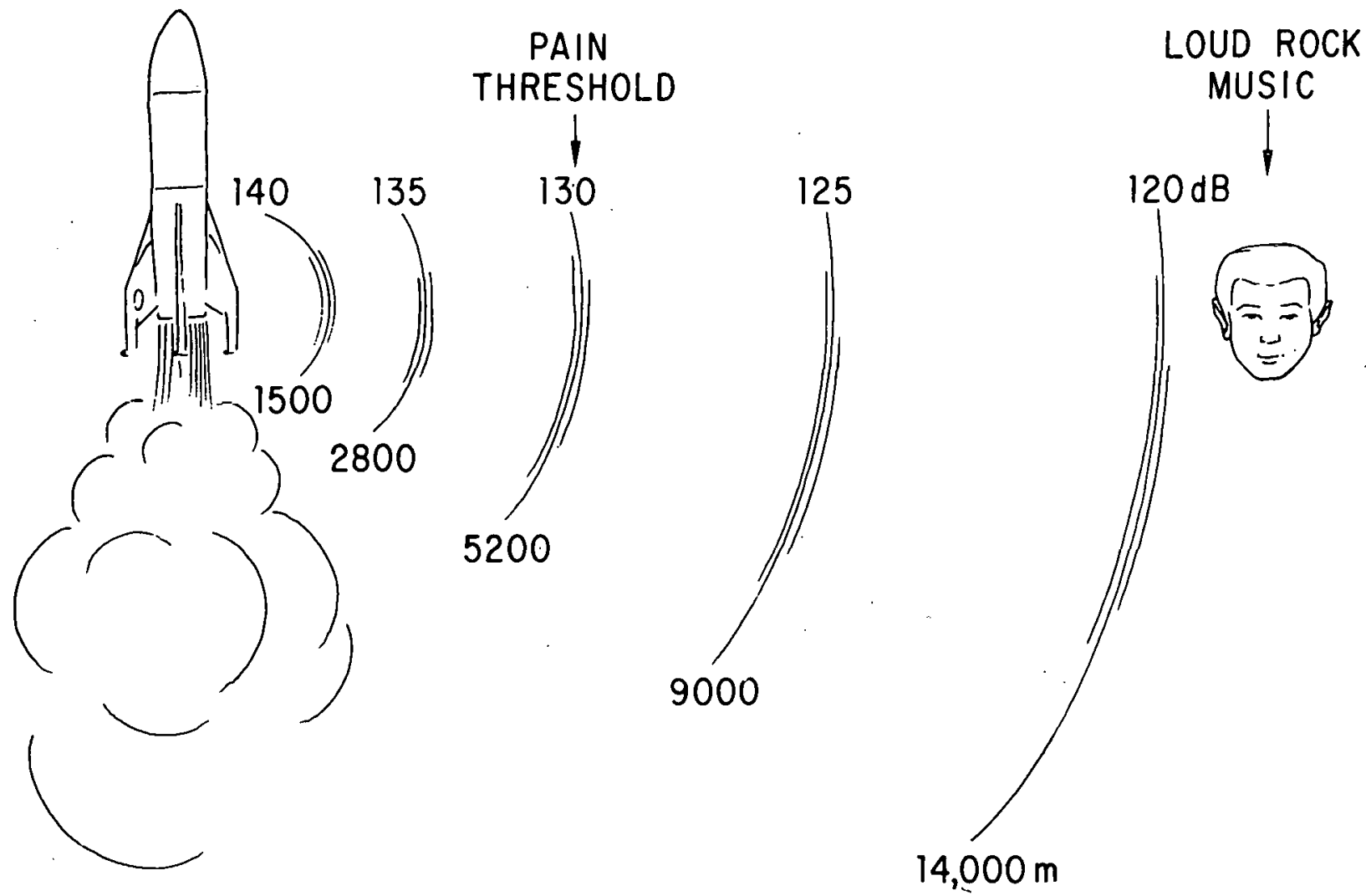

Fig. 2.6. Launch Noise. Profile

problems will be encountered. An analysis of SPS sonic boom generation will be needed to evaluate the extent of these impacts.

Launch and Recovcry Accidents. Acridental injury and/or fatality during during SPS launch and recovery operations can occur due to fire or explosion on the launch pad, launch abort, or landing accidents. The explosive potential of the HLLV is about twice that of a Saturn V. A catastrophic explosion during HLLV launch from Pad A of Launch Complex 39 at Cape Canaveral could cause Titusville, the nearest city, to experience an overpressure that would not result in structural failure but might cause injury by blowing out windows and doors.

No analysis has been done on SPS launch abort or recovery 1 anding accidents. These incidents are analogous to conventional aircraft accidents and, in the case of launch abort, would occur over controlled range areas and thus present no unusual problems. An evaluation of accident probability would be required tú estimare SRE effccto. 
High Intensity Electromagnetic Fields. At the rectenna site, an intense electric and magnetic field will be set up as a result of the high voltage power being transmitted from the satellite to the rectenna and from the rectenna to load center. The potential for public health effects from these fields is being studied in other ongoing programs, since the effects are not unique to SPS.

\subsection{EFFECTS ON TERRESTRIAL WORKERS}

The SPS effects on the health and safety of terrestrial workers can be measured in the same fashion as those on the public; that is, there is an increment in conventional mining, construction, manufacturing, and transport impacts and a set of effects resulting from unconventional conditions, as shown in Fig. 2.7.

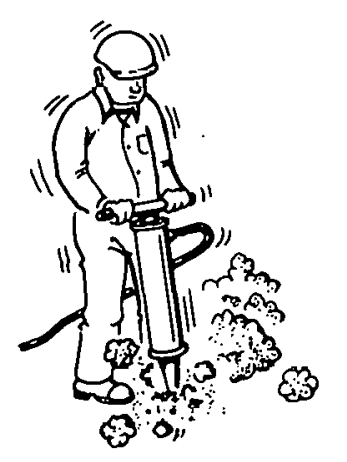

TERRESTRIAL WORKERS

NOISE

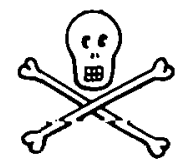

TOXIC

MATERIALS

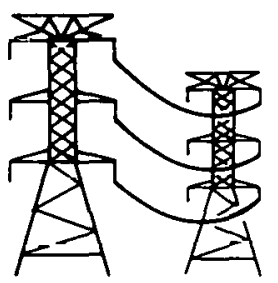

HIGH INTENSITY

EM FIELDS

FROM RECTENNA
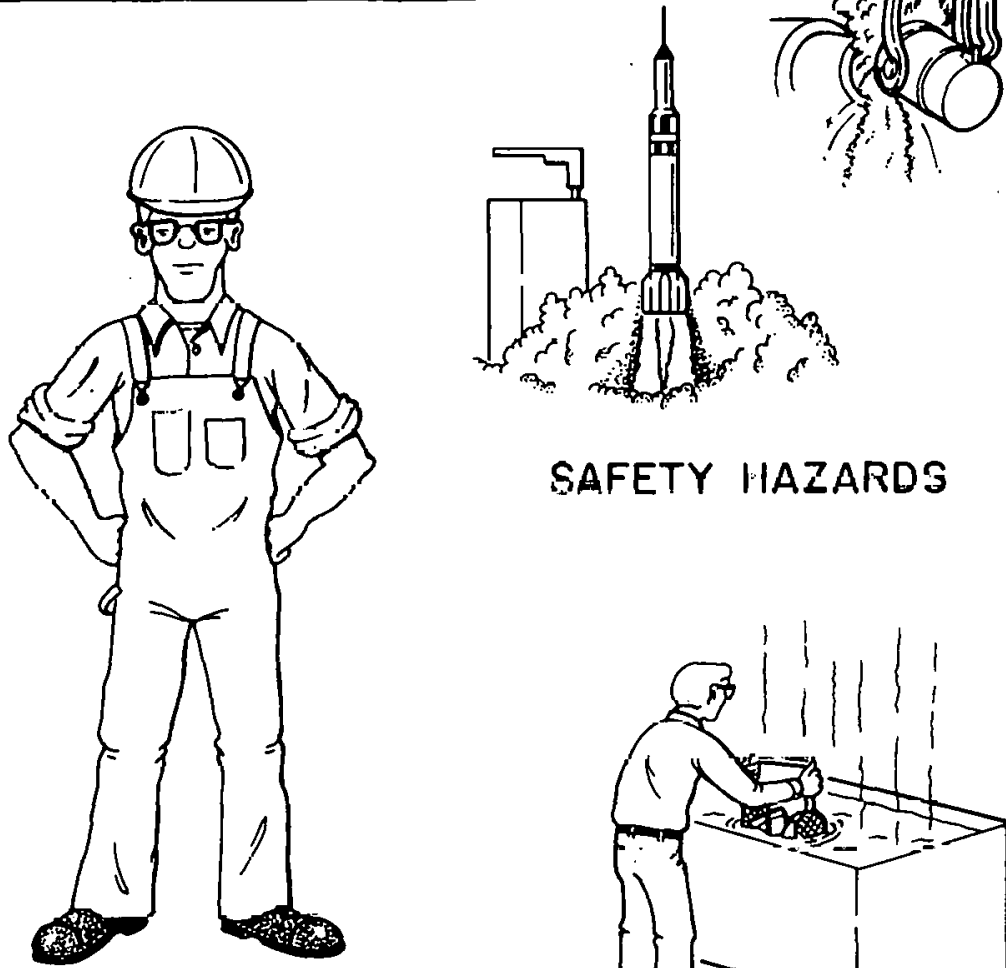

SAFETY HAZARDS

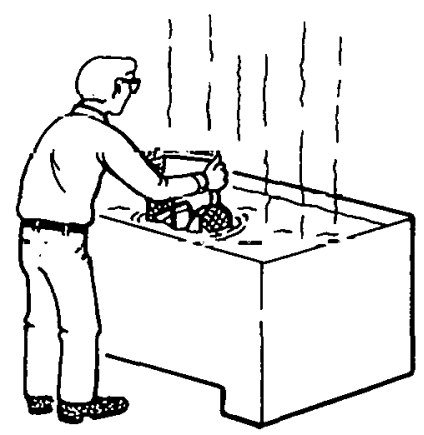

INDUSTRIAL AIR POLLUTION

Fig. 2.7. Nonmicrowave Effects of SPS on Terrestrial Workers 


\subsubsection{Impacts of Conventional Processes}

Figure 2.8 shows the results of an assessment of the distribution of occupational illness and injury by various functional activities carried out for an earlier SPS design. The information reveals that the material acquisition activities (i.e., mining) account for about half of the person-days lost for injury and illness and that the injury rate is much higher than the illness rate. These rates are totals over the 30-year life of a satellite power system and cannot be directly compared to published annual rates. The ongoing assessment will update these data to reflect more recent SPS design configurations.

\section{A PRELIMINARY OCCUPATIONAL HEALTH AND SAFETY ANALYSIS HAS BEEN DONE}

\section{MILLION PERSON-DAYS LOST: INJURIES}

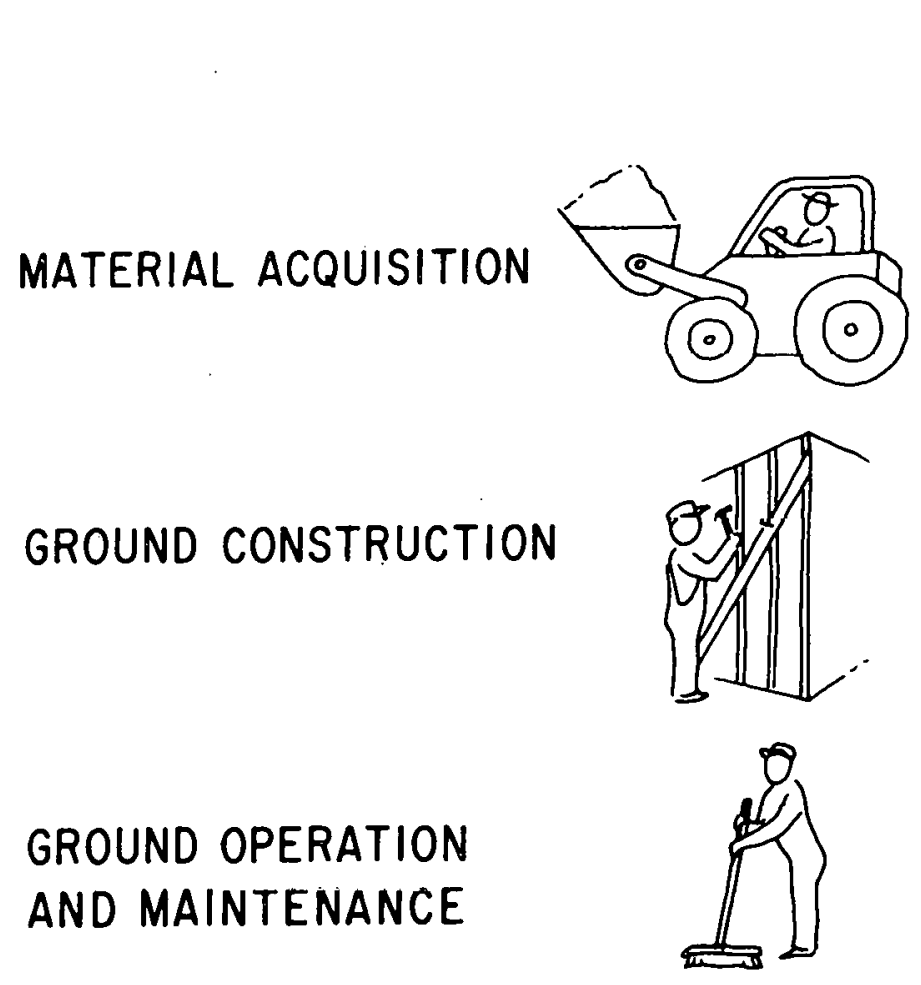

TOTAL

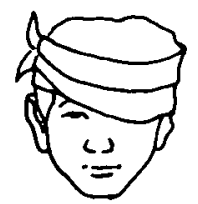

14.63

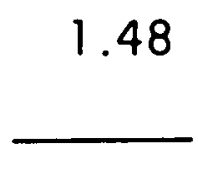

25.15

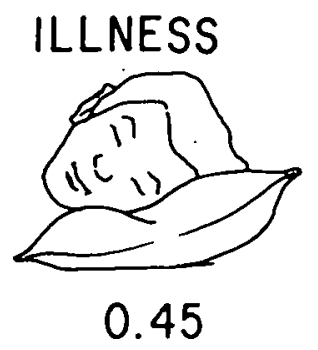

9.04

0.29

0.08

0.82

Fig. 2.8, Occupational Injury and Illness from Conventional SPS Causes 


\subsubsection{Unconventional Effects}

The unconventional effects on the health and safety of the terrestrial worker result from exposure to toxic materials, safety hazards from the transport of highly explosive materials, all of the launch and recovery activities, and exposure to high-intensity electromagnetic fields (other than microwave) at the rectenna site. These are the same effects as were discussed previously concerning public health and safety. The difference between public and terrestrial worker impacts is one of degree and intensity.

With regard to toxic material exposure, a toxic materials list, as already stated, has not yet been developed for SPS. A romplete evaluation of the effects of these substances must be made when all of the materials have been identified.

In transport accidents involving catastrophic explosions or fire, the workers involved (e.g., railroad crewmeṇ, emergency personnel, etc.) are more likely to suffer injury and/or fatality than is the general public, but this aspect must be evaluated when a more detailed assessment of accident probability is made.

The occupational health and safety effects of launch and recovery operations are known only insofar as they can be compared to conventional industrial operations (e.g., the use of threshold limit values for workroom air, the noise limits for workplaces, etc.). No systematic assessment has been made to date of the particular occupational health and safety problems created by SPS launch and recovery operations.

As with public health effects, the effests of high-intensity electrom magnetic tields on rectenna site workers' health have not been evaluated.

\subsection{EFFECTS ON SPACE WORKERS}

The health and safety problems related to the uniqueness of the space environment are illustrated in Fig. 2.9. Some of the more important problems are weightlessness (zero gravity), life support, and the effects of the radiation environment. 


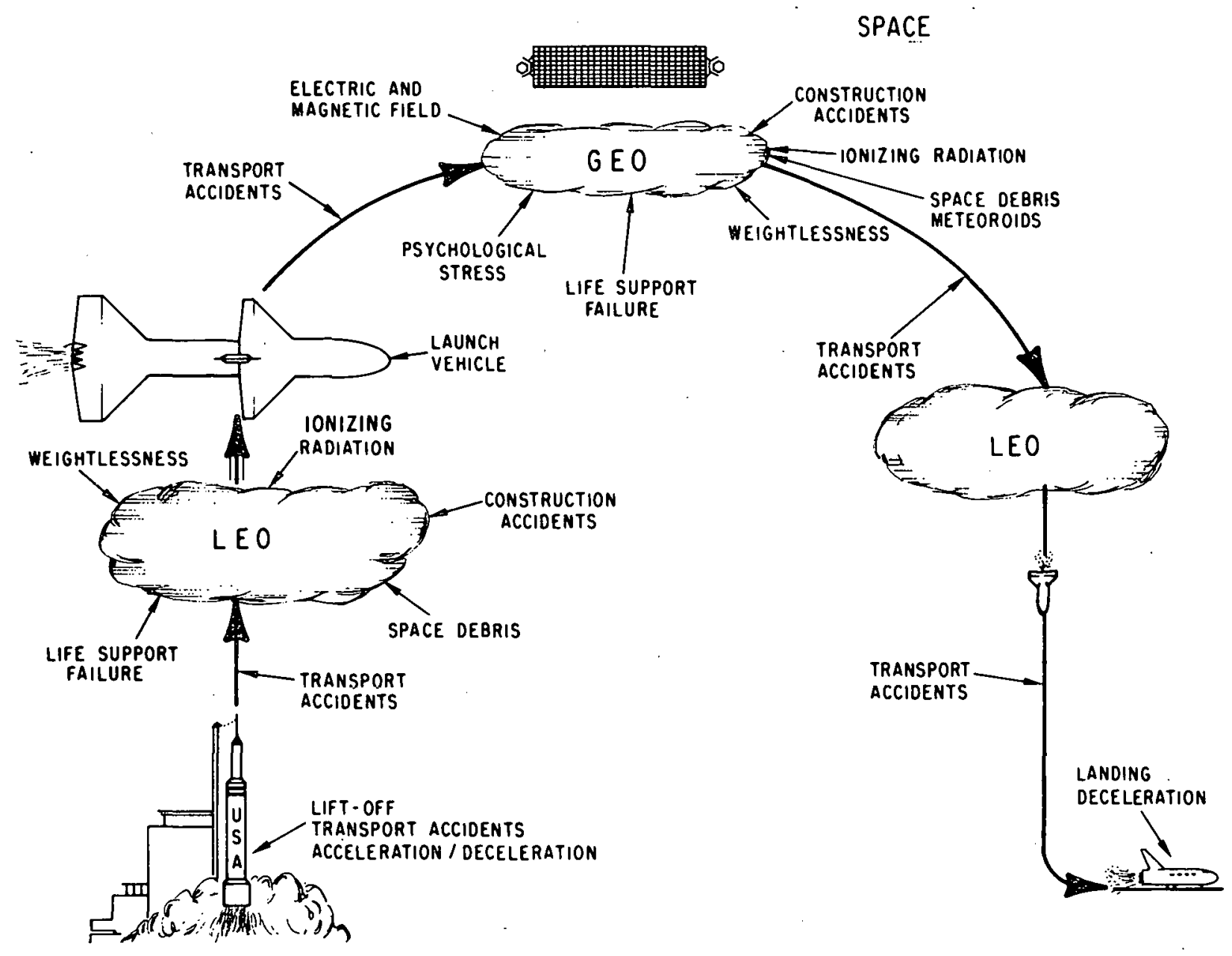

Fig. 2.9. Nonmicrowave Effects of SPS on Space Workers

\subsubsection{Weightlessness}

In previous space flights, a number of physiological and biochemical alterations were observed in the astronauts. The most important of these appear to be:

- Anemia (reduced number of red cells),

- Cellular immune system changes,

- Plasma volume reduction (i.e., reduction in the fluid components of the blood),

- Calcium luss frum the bones,

- Muscle tissue reduction;

- Blood chemistry changes,

- Vestibular problems (i.e., space motion sickness, dizziness, spatial disorientation, sensations of rotation), and

- Fat loss (inadequate nutrition?). 
Some of these changes may be simple adaptations to a unique situation for humans, and there appears to be some adaptation in which a new equilibrium is approached as time in space is extended. Other effects, such as calcium loss, continue throughout space flight (up to 84 days in Skylab). NASA's continuing research on these problems may lead to ways of ameliorating their effects. This research will be assessed for possible long-term and short-term effects on the health of space workers.

\subsubsection{Life Support}

For SPS, with the projection of longer stays in space and constructiontype activities, life support systems used in earlier space flights need to be carefully evaluated and modified. Some problem areas may be:

- Correct nutrients in food,

- Recycling of air and water,

- Toxic air contaminants from such sources as out-gasing of construction materials, waste products, etc.,

- Medical and dental emergency facilities, and

- Psychological stresses.

NASA is doing research and/or studies on these problems. This work will be assessed relative to the unique aspects of SPS and evaluated to identify possible deleterious effects on space workers.

\subsubsection{Radiation}

The amount and types of ionizing radiation to which space workers are exposed may limit the length of stay in space. Workers will be exposed to:

- Galactic cosmic radiation [protons, alpha particles, and high-energy heavy ions (HZE)],

- Solar-particle events,

- Trapped electrons and protons, and

- Radiation from onboard radioactive materials (extent unknown at present).

Studies using currently available data are assessing the potential radiation doses to space workers in transit, in low earth orbit (LEO), and in geosynchronous earth orbit (GEO). Biological effects of electrons, alpha 
particles, and protons are discussed in the literature and are the subject of current research. The biological effect of $\mathrm{HZE}$ is less well known, and it appears that more research needs to be done on these particles in order to better define their effects.

Workshops and/or peer reviews of the current knowledge of the radiation environment will be conducted. Recommendations regarding the possible effects will be made, and if it appears necessary, future research will be recommended to clarify subjects for which there is insufficient knowledge for assessment.

Other types of radiation and particles, which have not been assessed because of lack of time or lack of complete systems' definition, may cause problems. These are:

- Magnetic field,

- Electrical field,

- Plasma arcing,

- Space debris, and

- Meteoroid collisions.

\subsection{EFFECTS ON THE ENVIRONMENT}

A variety of activities relating to construction and operation of SPS could affect terrestrial and aquatic ecosystems. Among these impacts are:

- Air and water pollution,

- Land disturbance,

- Electric field effects,

- Reflected light from satellites, and

- Noise.

The construction/operation activities should be thoroughly identified, and their impacts predicted. Where warranted, mitigation procedures should be developed before such activities are initiated.

Some information is available from previous space flights and from NASA's ecological research. These data need to be put into the context of SPS systems' definition (i.e., the number of flights, the types of fuels used, etc.), in order to predict the effects on the environment. Time and information, to date, have been inadequate to make quantitative assessments.

Construction activities, as well as the emissions of a variety of pollutants, are known to alter ecosystems by changing the character of plant 
and animal communities. These impacts $c$ an be assessed once specific development procedures and ecosystems are identified. Certain additional potential impacts will be more difficult to assess due to a lack of information in the scientific literature. The areas of concern include fragmentation of ecosystems, electric field effects, the possibility that some species of wildife may be attracted to the rectenna in large numbers, and the possible disturbance of the rhythmic cycle (e.g., reproduction, dormancy, etc.) in plants and animals by reflected light from satellites.

Construction and nonmicrowave operational aspects of SPS have the potential to impact large arcao of natural and man-altered ecosystems. The responses of ecosystems to various types of physical disturbances are much better known than are the responses to microwaves. For this reason, there is probably no need for a large, experimental ecological research program for nonmicrowave effects. However, a preliminary, nonexperimental research program should be initiated.

Ecological impacts may vary with the specific construction techniques used, and even those methods that have minimal impact in one ecosystem might have a severe adverse impact when used in a different ecosystem. It is possible that limited experimental research might be required to answer some critical nonmicrowave questions. A preliminary nonexperimental research program will determine whether such questions exist, and establish priorities if they do. 


\section{EFFECTS ON THE ATMOSPHERE (INCLUDING CLIMATOLOGY)}

The natural atmosphere contains both electrically neutral and ionized constituents. Whereas the neutral species are distributed throughout the entire atmosphere, significant populations of ionized species are found only at altitudes greater than about $60 \mathrm{~km}$. The characteristic physical and chemical properties of the natural atmosphere and atmospheric processes provide a convenient means for separating it into a series of layers beginning with the troposphere, in which weather phenomena occur, and ending with the exosphere, which reaches out to the region where terrestrial space and outer space merge (see Fig. 3.1). Overlapping these general atmospheric layers are a series of layers containing ionized atomic and molecular species electrically balanced by an equal number of free electrons. Superimposed on the upper layers is a region referred to as the magnetosphere. While it is true that the earth's magnetic field extends from the surface out, the magnetosphere is that portion of the outer magnetic field (above about $150 \mathrm{~km}$ ) in which the motion of charged particles is dominated by magnetic forces instead of by the particle collisions characteristic of molecular diffusion.

The investigation of atmospheric effects associated with the SPS has been divided into task areas that take advantage of the naturally occurring atmospheric layering. Of course, it is important to realize that while the various atmospheric layers are to some extent isolated from one another, mechanisms do exist that naturally couple adjacent layers. Hence, whereas the SPS may influence specific layers of the atmosphere directly, for example by the discharge of rocket propellants, such layer-specific influences may be subsequently propagated to adjacent layers either by naturally-occurring or inadvertantly-formed coupling processes.

Figure 3.2 shows a few of the general types of atmospheric effects expected to result from rocket launches. Whereas all of the processes illustrated in the figure are expected to occur, the magnitudes of the effects and their consequences for climate and weather, radio wave propagation, and other phenomena of importance to public health and welfare or the ecology remains uncertain. Not illustrated in Fig. 3.2 but also of potential importance are effects associated with rectenna operations, including effects of the transmission of microwave energy through the troposphere. 


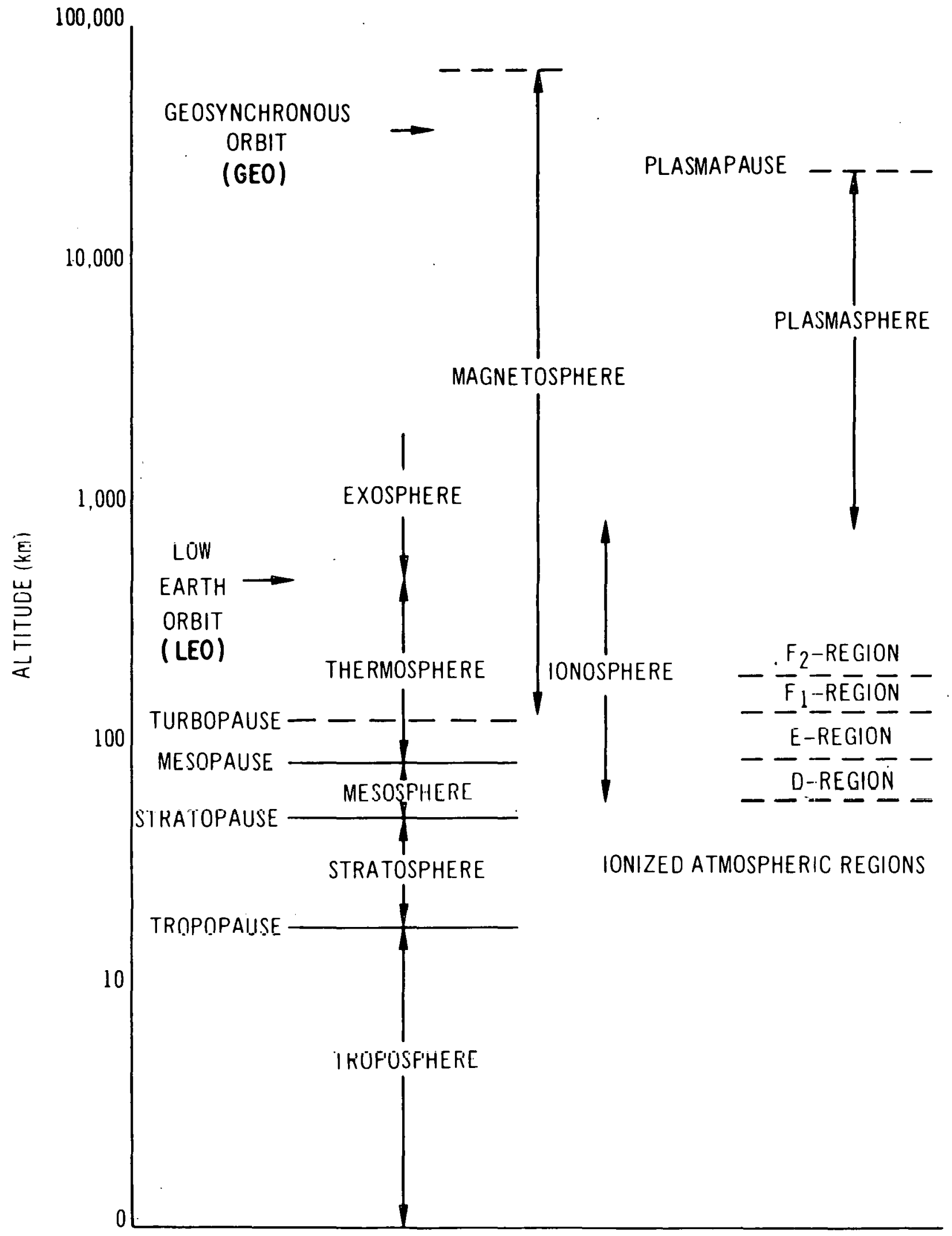

Fig. 3.1. Regions of the Atmosphere 


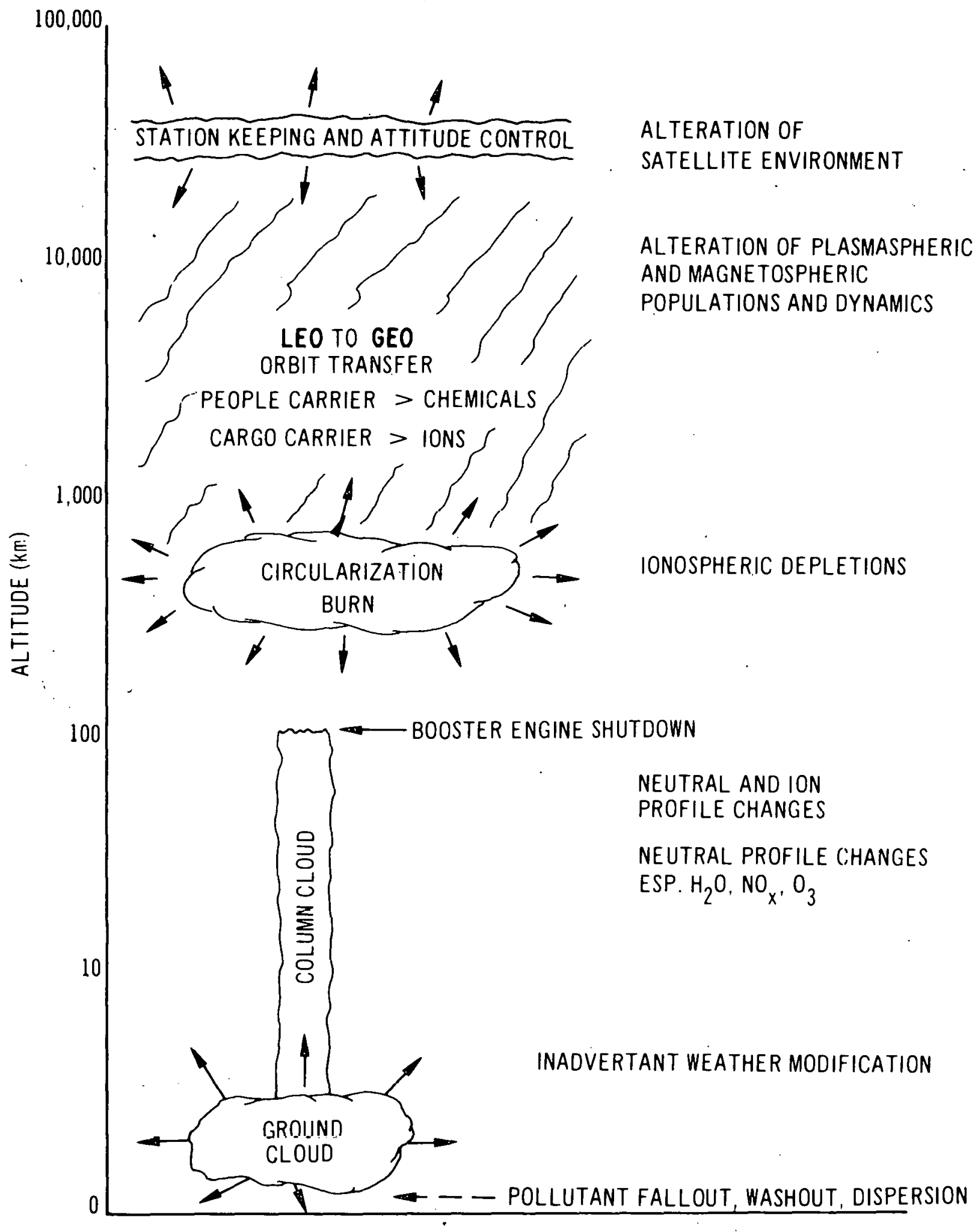

F1g 3.2. Summary of Some Potential Atmospheric Effects Caused by Rocket. Exhaust. 
Preliminary investigations have resulted in an understanding of our present state of knowledge and our ability to predict the occurrence of atmospheric effects and their subsequent impacts. Thus far it has been possible to identify at least initial or direct atmospheric effects and, in some cases, cause and effect "chains" or sequences of events resulting from SPS disturbances in various regions of the atmosphere. However, the extent or magnitude of these effects and what consequences they may have for the biosphere will have to be more intensively studied during FY 1979 and FY 1980 and perhaps for many years to come, especially if any program of the magnitude of the SPS is actually undertaken. Pilot programs, if they are initiated, should be carefully monitored for information useful in verifying theoretical predictions or in identifying new issues. Below are summarized some of the more important issues that have been identified and for which further investigation is under way or planned.

\subsection{MICROWAVE AND RECTENNA-RELATED EFFECTS IN THE TROPOSPHERE}

Possible relationships between the rectenna and weather and climate modifications are shown in Fig. 3.3. Preliminary qualitative analyses have indicated that the waste heat released at the rectenna site would produce about the same heat-island effects as a suburban area. Those analyses also showed that under most situations, the attenuation of the microwave beam in the troposphere will be small and will not produce significant disturbances of meteorological consequence on any scale. More recently, however, in a workshop on the meteorological effects of SPS rectenna operation, the panel recommended that increases in waste heat release of up to an order of magnitude should be considered in order to account for the possible loss of beam control in worst-case situations. They also recommended that the effects of atmospheric heating due to rectenna operation should be better defined on both the mesoscale (10-i00 km in size) and "cloud scale" (10 km or less). The effects, as pointed out by the pane1, will vary from one atmospheric condition to another and hence will be site specific. However, not all conditions can be tested in the two-year feasibility study period and so a few typical configurations of flat land, ocean, and mountain-valley situations should be focused upon using existing mesoscale and "cloud scale" models. Site-specific and characteristic regional effect studies of SPS should be considered as longer term objectives. 


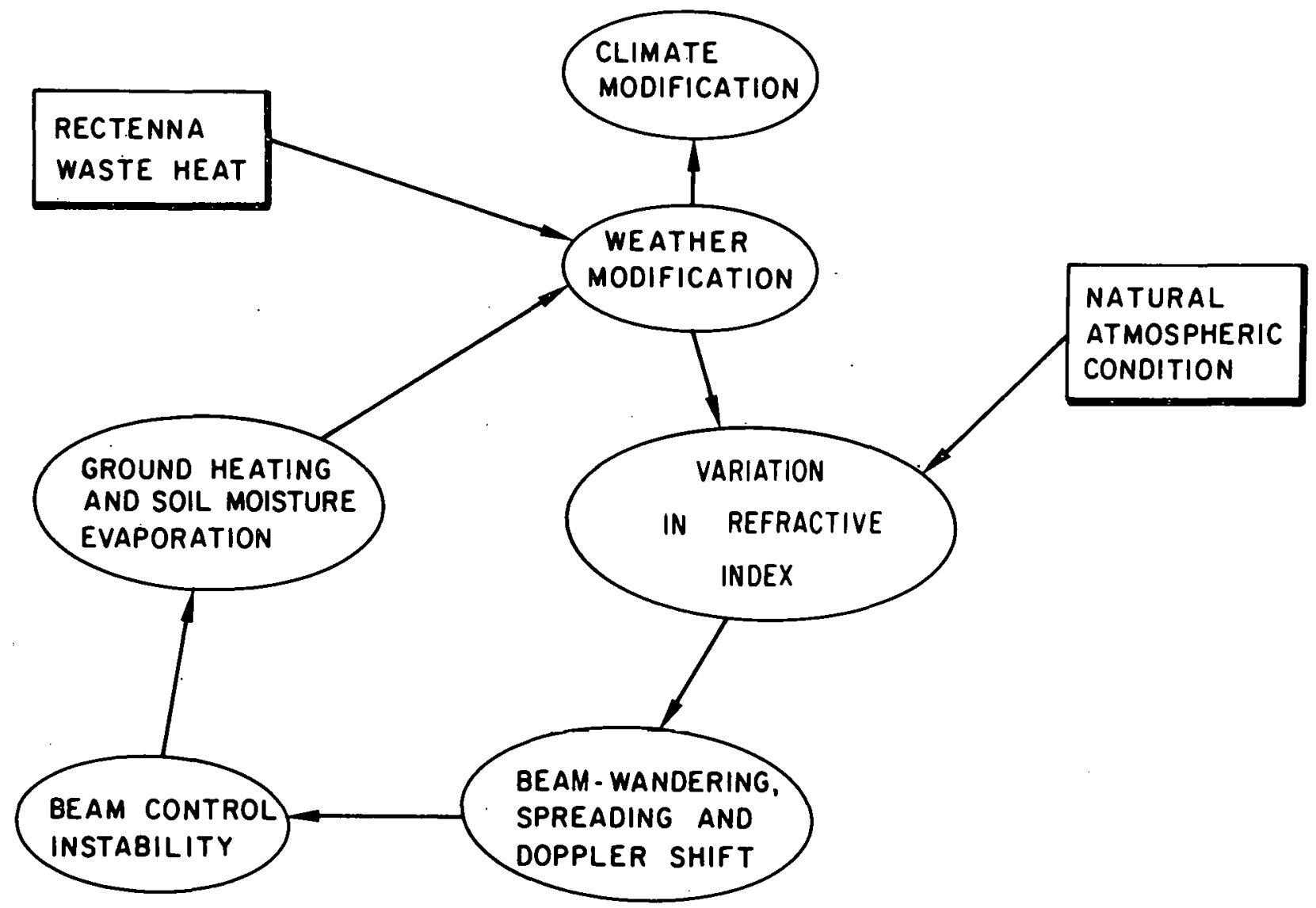

Fig. 3.3. Climatological and Heating Effects of the Microwave Power Transmission System in the Lower Atmosphere

Variations in the refractive index of the atmosphere and the presence of hydrometeors (droplets, raindrops, hail, ice crystals, etc.) in the atmosphere cause refraction, scattering, and absorption of electromagnétic waves. At $2.45 \mathrm{GHz}$ the refractive index of air at fixed pressure depends mostly on water vapor and temperature. In the presence of convective or turbulent air motions, a spectrum of atmospheric refractivity variations develops which can lead to beam wandering and spreading. The scattering and absorption by hydrometeors depends on their size, shape, number, concentration, and composition. If these properties are specified, atmospheric attenuation and beam spreading can be calculated. Contributions to beam wandering and spreading from the planetary boundary layer, cloud systems, jet stream turbulence, and stratified atmospheric layers must all be considered.

These atmospheric effects on electromagnetic propagation contribute to the power beam and pilot beam stability problems. Slowly varying and 
drifting anomalies, large-area events, or numerous smaller-area anomalies in the power beam and the pilot beam cause spatial and temporal modulations that vary the illumination of the ground-based rectenna, and under adverse geometry, can cause large variations in pilot signal parameters. The latter have a strong potential for causing serious ambiguities in the control decisions and system stability considerations.

An issue that has received only cursory attention is the effect on atmospheric electricity of the power beam and the rectenna. Direct interactions between the power beam and the atmospheric electric fields are not thought to be crucial at the $2.45 \mathrm{GHz}$ frequency. However, the mere physical presence of the rectenna may have some modifying influence on the occurrence and electrical behavior of thunderstorms over and around the rectenna. Further study is needed in this area.

Finally, electric and magnetic fields in the vicinity of the rectenna and the transmission lines may have biological as well as meteorological significance, especially if direct-current power is used. The anticipated field strengths will have to be determined based upon SPS design parameters and previous experience with existing direct-current, power-transmission systems.

\subsection{NONMICROWAVE ATMOSPHERIC EFFECTS ABOVE $60 \mathrm{KM}$}

Above $60 \mathrm{~km}$ the population of ionized atomic and molecular species becomes significant. Consequent1y, deposition of rocket effluents above $60 \mathrm{~km}$ can affect natural processes involving neutral and ionic species as well as the magnetosphere that is coupled to the ions by electromagnetic interactions. Between 60 and $500 \mathrm{~km}$ (low earth orbit is at approximately $500 \mathrm{~km}$ ) the atmosphere is subject to modification from rocket thruster effluents. The main source of SPS-related disturbance comes from chemical rocket exhaust products, including water, carbon dioxide and smaller quantities of various other effluents, including carbon monoxide, oxides of nitrogen, and unburned fuel (hydrogen and methane). Space vehicle reentry will also contribute some effluents such as ablated materials and oxides of nitrogen to the lowest layer of this region. 
So far, calculations have shown that one of the major atmospheric effects of rocket effluents will occur in the ionospheric layer referred to as the F2 region (see Fig. 3.1). Here, exhaust products act to remove a large fraction of the total number of electron-ion pairs from the ionospheric region surrounding the position of the rocket burn. In the case of the 1973 NASA Skylab launch, the depleted region covered an area $2000 \mathrm{~km}$ in width for a period of several hours. Similar depletions, but of smaller scale, have been deliberately created in the 1977 experiments named LAGOPEDO. Theoretical predictions verified by these observations included enhanced airglow (visible emissions from excited molecules) and electron-ion pair depletion. Additional experiments and further analysis of data will be required to verify the occurrence of thermal effects and the formation of plasma striations that can cause interference with radio communication systems. The enhanced airglow, while not sufficient to cause harmful effects at ground level, may contribute to the background interference to optical sensing devices employed in sate1lite surveillance systems. The potential impacts of electron-ion removal and possible thermal effects are not well understood at this time and will be examined during FY 1979 and FY 1980, as will the nature and extent of the depletions themselves. To date only individual rocket launch effects have been observed and only preliminary calculations of multiple launch effects have been attempted. Much more theoretical emphasis will be placed on multiple rocket launch effects in the future.

Beyond $500 \mathrm{~km}$ the major rocket propulsion system effluents will be heavy ions (argon ions) with smaller amounts of chemical propellants. Preliminary calculations suggest that the mass and energy increase in the plasmaspheric region surrounding the satellites will be substantially increased during transfer of the satellite cargo from low $(550 \mathrm{~km})$ to geosynchronous $(35,000 \mathrm{~km})$ earth orbit. The impacts of such increases will be undertaken and some experiments have been suggested to improve our understanding of these effects during the next two years.

The SPS satellites themselves, composed of large metallic structures, may pose some hazards to the environment both in the vicinity of the satellites and perhaps even closer to the biosphere. First the satellites will tend to collect particles as they sweep through the ambient plasmasphere. Second, they may develop fairly large electric and magnetic fields as a result 
of motion relative to the earth's magnetic field and the accumulation of ions. Third, the satellites may be significantly weathered by cosmic ray and meteoroid bombardment. Finally, they will reflect substantial quantities of visible sunlight (that could be either diffuse or well focused, depending on the nature of the metallic surfaces) and radiate substantial amounts of heat energy (infrared radiation). While preliminary calculations of these effects have already been carried out, better estimates of source-terms, that is, magnitudes of emission rates, will be necessary to obtain improved estimates of environmental impacts.

\subsection{NONMICROWAVE EFFECTS ON THE STRATOSPHERE/MAGNETOSPHERE}

The potential exists for significant impacts due to injections of water at altitudes above about $40 \mathrm{~km}$ and to the production of nitric oxide in the mesosphere during the reentry of the second stages of the HLLV and personnel launch vehicle second stages. More detailed calculations are required to properly assess these impacts. In addition, because of deficiencies in our understanding of physical and chemical processes above 40 or $50 \mathrm{~km}$, especially with regard to the water budget, a significant uncertainty must be associated with any theoretical prediction. The need for additional research in this area is great and a significant effort should be directed towárd increasing our understanding of the water budget and of the mesospheric environment in general.

Rocket exhaust emissions of carbon dioxide are not expected to have a significant impact, nor is the production of nitric oxide in the exhaust plume by afterburning processes.

Climatic effects that may arise from SPS-related perturbations in stratospheric and mesospheric composition are not expected to be highly significant, although considerable uncertainty exists in this regard. A much more deralled analysis is required, including, specifically, an assessment of the possible effects of increased cloud formation due to injections of water into the mesosphere. 
4 EFFECTS ON COMMUNICATION SYSTEMS

\subsection{ELECTROMAGNETIC COMPATIBILITY}

\subsubsection{Methodology}

The radiated power and planned operating frequency of the SPS indicate the importance of the electromagnetic compatibility (EMC) evaluation relative to radio frequency systems and other susceptible electronic systems that operate within the continental U.S. and adjacent international areas. All electromagnetic emissions from the SPS (primary, harmonic, and spurious; and associated spatial patterns) are being assessed, with the goal of determining the spatial distribution of interference power densities as well as determining ionospheric and atmospheric media effects on the primary and sidelobe beam characteristics. Interference power densities are used to determine the character of performance degradation for radio frequency and electronic systems, scored relative to the ranges of signal-to-interference ratios possible over the operational geographical areas. A pictorial representation of the SPS and candidate interference problems in Fig. 4.1 indicates the scope of this investigation.

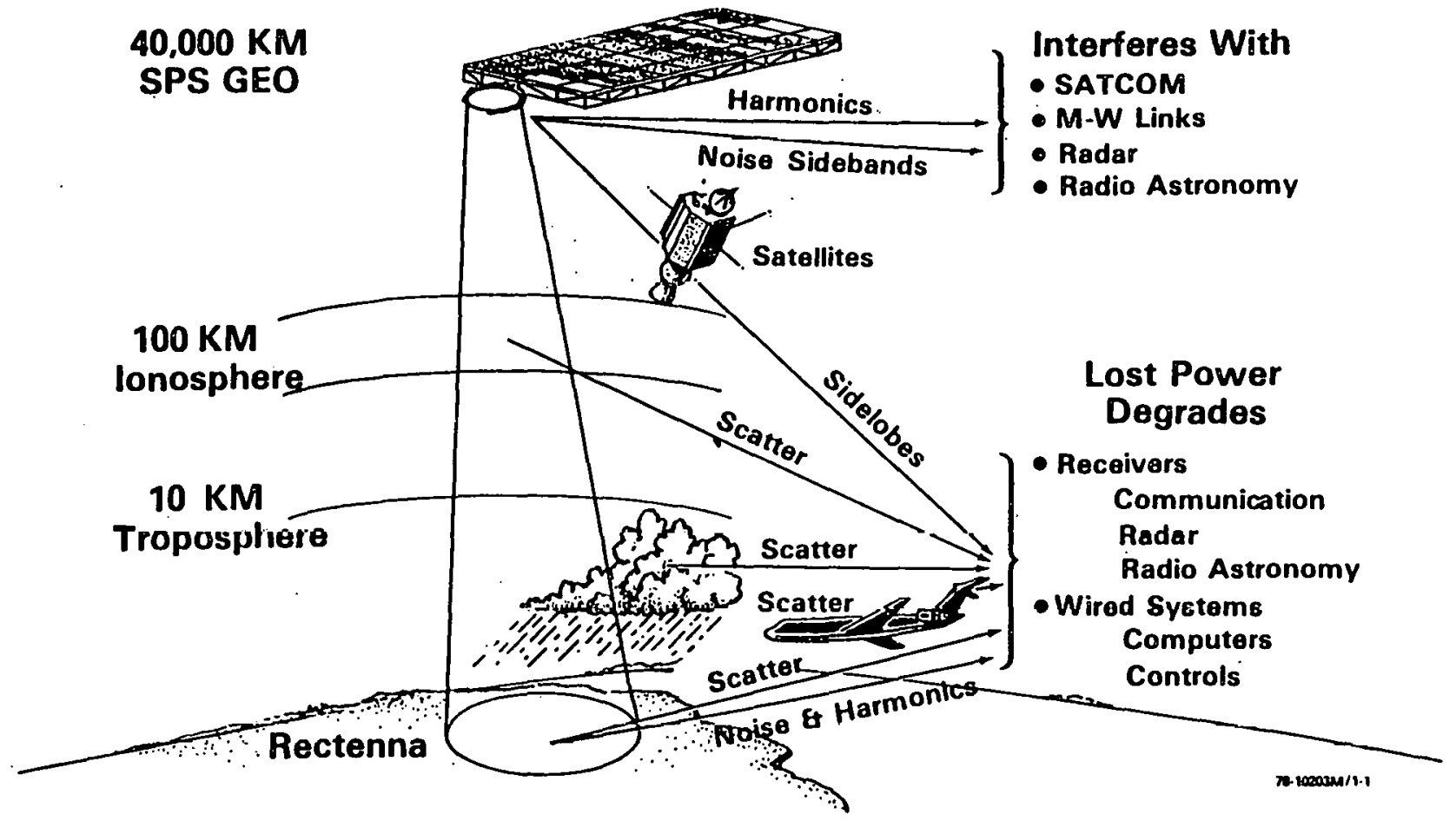

Fig. 4.1. SPS Radio Frequency and Electromagnetic Interference 
To evaluate the impact of equipment/system performance degradation, the resultant operational compromises are derived. Operational considerations include, for example, equipment/system criteria relationships to the safety and effectiveness of supported activities (e.g., mass transportation, traffic control, military surveillance/weapons delivery, communications network efficiency), in terms sufficiently detailed to support national impact extrapolation and cost-benefit analyses. Based on the impact and cost-benefit findings, recommendations will be made for mitigating system degradation.

The basic analysis elements, including the SPS environment, equipment/ system degradation, and operational implications, are depicted in Fig. 4.2. lhésè elements include propagation media, affected system performance, and representative operational impact areas.

Mitigation techniques emphasize degraded equipment energy penetration and coupling mechanisms, antennas, circuitry, cabling, etc. Recommendations for equipment modifications will concern these areas and will take into account cost-benefit trade-off results.

Two series of technical reports will be developed. One series will examine functional system degradation and the operational support implications

DATA

1. SPS

System

Specifications

2. Candidate Rectenna Sites

3. Area Meleoioloyy

4. Susceptible Equipment Locations paramerers
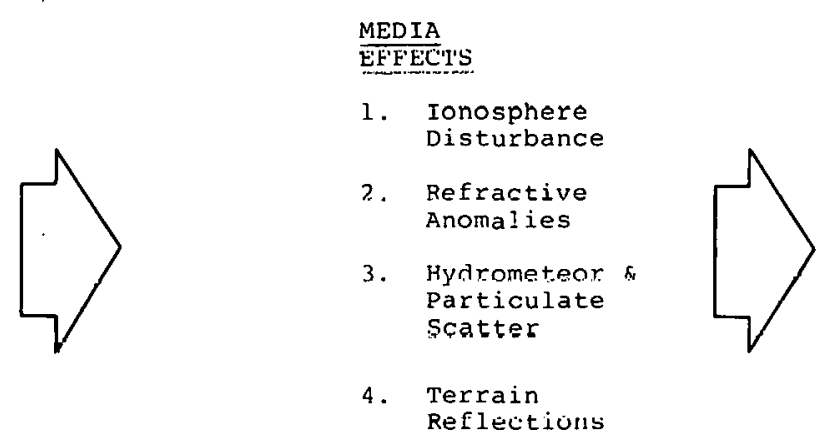

$$
\text { Reflections }
$$

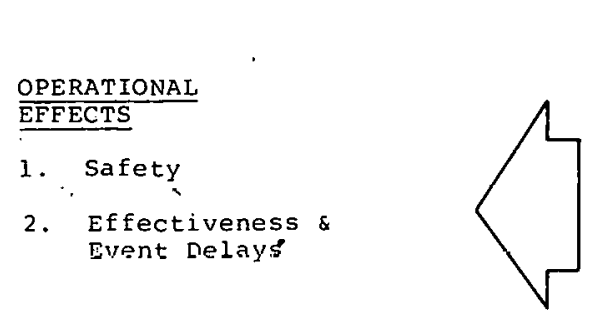

ENVIRONMENT SPECIFICATION

1. Area

Power

Densities

2. Interference Amplitudes

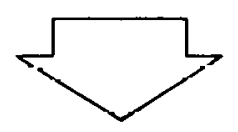

INTERFERENCE UEGKAD̈ATIUN

1. SPS Energy Coupling

2. Interference Induced Performance Degradation

Fig. 4.2. Basic EMC Analyses Elements 
for the areas near proposed rectenna sites, hemispherical SPS power: densities for multiple satellite systems, and mitigation techniques, and present recommendations for the various interfered system categories. The second series will contain guidelines for EMC analyses of future system deployments in the rectenna areas to assure acceptable performance.

\subsubsection{State of Knowledge}

The EMC evaluation program uses various propagation models to determine SPS illumination power at specific locations and general areas within the continental United States, and equipment/system functional models to derive signal-to-interference degradation characteristics. for the SPS primary and harmonic emissions. The propagation modes cover line-of-sight attenuation, hydrometeor and particulate attenuation and scatter, atmosphere anomaly refraction, and terrain and structural reflections. Mainly because of the high power level of the SPS, limited media model refinements are required for particulate scatter and anomaly refractive effects.

System degradation models for communications, radar, and other radio frequency components are adequate for military, industrial, and commercial applications. These models include in-channel and out-of-band interference effects.

Existing coupling and effect descriptors for optical and electromagnetic sensors, and various computer and processing/control circuitry (distributed and integrated circuit configurations) provide an adequate base for the initial analyses. Additional measurements will be made so that modular effects can be sufficiently defined to support realistic specification of mitigation techniques. These measurements and sensitivity testing, using existing functional and circuit models, are also necessary to support the cost-benefit trade-off exercises for the mitigation techniques.

The SPS system data required for these electromagnetic compatibility analyses are provided by the SPS concept definition program. Data required encompass satelite spectral and spatial emission characteristics, rectenna candidate locations and functional parameters, and control processes. 


\subsubsection{Preliminary Assessment}

After a number of candidate rectenna sites were identified in a NASA report, * the Mojave rectenna site was selected for detailed study. The initial electromagnetic compatibility analysis addressed the Mojave site to provide electromagnetic impact data for the site characteristic review, and contribute to the development of site selection criteria for NASA and DOE.

The Mojave site center coordinates are $35^{\circ} 8^{\prime}$ north latitude, $117^{\circ} 30^{\prime}$ west longitude. The rectenna covers an area of roughly $100 \mathrm{~km}^{2}$. Figure 4.3 shows a main beam and sidelobe structure for the assumed SPS spacetenna. In

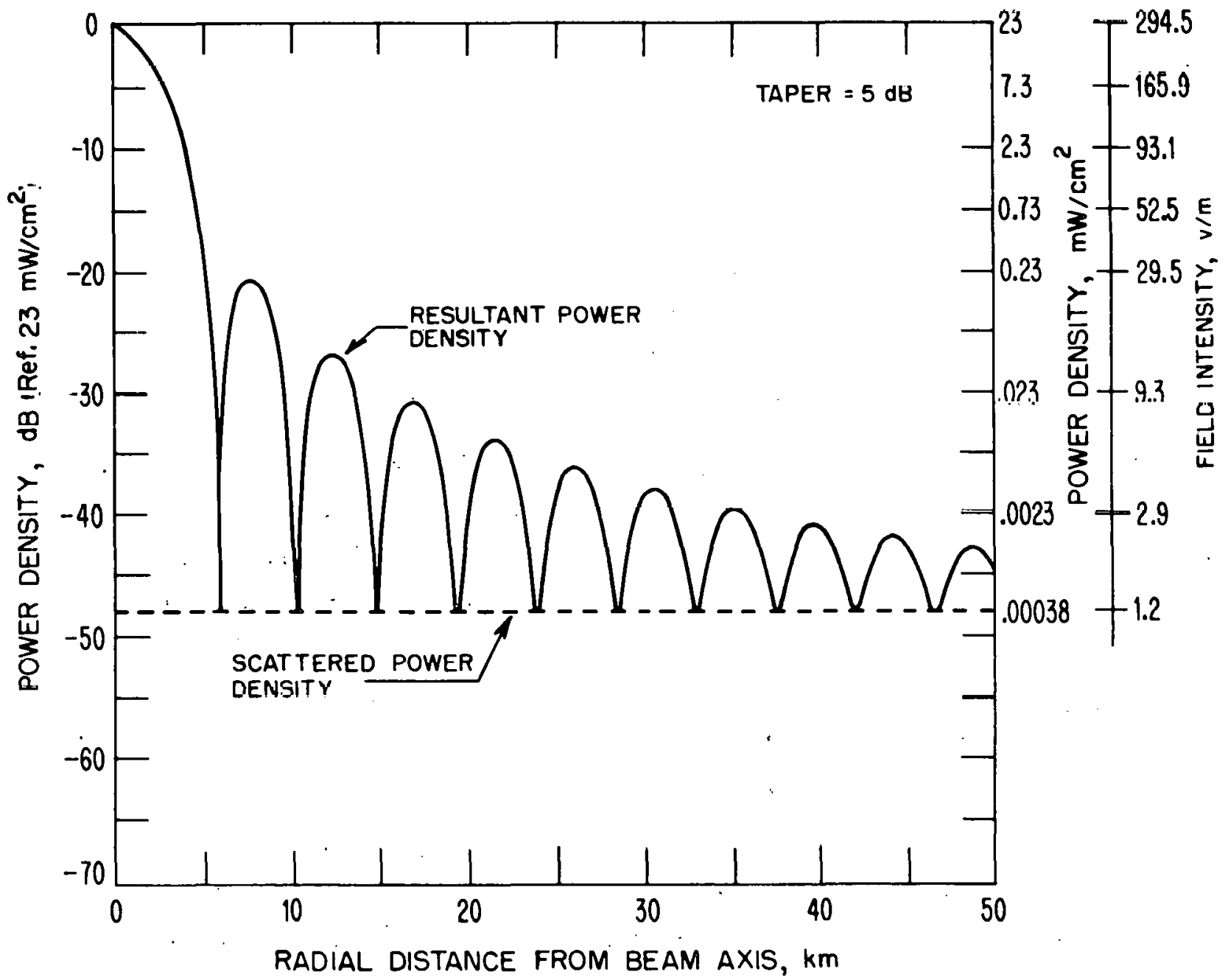

Fig. 4.3. SPS Transmitting Antenna Pattern

*Candidate Locations for SPS Rectifying Antennas, NASA-TM-78146 (Nov. 1977). 
In dealing with communications systems, field intensities measured at an antenna are given in microvolts per meter $(\mu \mathrm{V} / \mathrm{m})$. For high power televisions or AM and FM broadcast stations, the field intensity beyond a mile, but within 20 or $30 \mathrm{miles}$, may normally be in the millivolts per meter $(\mathrm{mV} / \mathrm{m})$ range. For the average TV owner, the field intensity measured at the home antenna would most likely be in the microvolt per meter range. This comparison will help to put the amount of energy beyond the rectenna site, due to sidelobe structure, in proper perspective.

Referring back to Fig. 4.3., the right-hand scale has two number values. One is power density in milliwatts per square centimeter $\left(\mathrm{mW} / \mathrm{cm}^{2}\right)$ and the other is field intensity in volts per meter. Note that the field intensity beyond $50 \mathrm{~km}$ from the center of the rectenna site would still be $1 \mathrm{~V} / \mathrm{m}$ at $2.45 \mathrm{GHz}$ frequency. This intensity represents a sizable input to communication systems operating within $100 \mathrm{~km}$ of the rectenna site. Added to the electromagnetic field, due to sidelobes, is the power scattered from the main beam from media effects.

Assessments have been made at five sites surrounding the rectenna site in the Mojave. These sites represent relatively large deployments of highpriority military operations. Those sites and their distances from the rectenna are given in Table 4.1 .

Propagation mechanisms for SPS energy include loss, and beam scattering and multipath components.

- Sand storms,

- Rain,

- Me1ting hail,

- Atmospheric layers (multipath),

- Atmospheric aerosols, and

- Turbulence.

Table 4.1. Selected Site Distances from Mojave Rectenna

\begin{tabular}{ll}
\hline SPS - China Lake Airstrip & $64 \mathrm{~km}$ \\
SPS - Downtown Barstow & $51 \mathrm{~km}$ \\
SPS - Edwards AFB Airstrip & $43 \mathrm{~km}$ \\
SPS - Restricted Area R 2524 & $53 \mathrm{~km}$ \\
SPS - George AFB Airstrip & $61 \mathrm{~km}$ \\
\hline
\end{tabular}


In addition, energy will be scattered by the terrain and by the rectenna surface. Rain and hail would be serious problems if the rectenna were located elsewhere than the California desert. To show the magnitude of rain, for example, statistics were gathered from the nearest site where records are kept.

Rainfall data for Bakersfield, California are used as representative of rainfall to be found in the SPS receiving site vicinity (although it is still a considerable distance away and somewhat lower in elevation). Bakersfield receives rain at a rate of about $9.1 \mathrm{~mm} / \mathrm{hr}$ on the average of about one hour per year, and at the extreme (one year out of 200 ) receives $17.3 \mathrm{~mm} / \mathrm{hr}$ for one hour during a year. For about five minutes of an average year, Bakersfield receives rain at a rate of $19.3 \mathrm{~mm} / \mathrm{hr}$, and at $47.2 \mathrm{~mm} / \mathrm{hr}$ at the one-out-of-200-year extreme for five minutes of that year. Based on the work of Dutton,* the height of a storm that will produce the aforementioned rain rates at the earth's surface can be predicted. The results are shown in Table 4.2 based on Bakersfield data for average conditions. These magnitudes could be of considerable importance to systems operating in such an environment.

The amount of potential electromagnetic energy from all forms of scatter, including that from the rectenna itself (not calculated yet), added to the power from the sidelobes, presents a formidable problem for systems as far as $100 \mathrm{~km}$ from the rectenna.

To assess the impact on systems near the Mojave oite, an arca $145 \mathrm{~km} \mathrm{by}$ $145 \mathrm{~km}$, with the proposed rectenna site at the center, was chosen as a data sample area. Al government and nongovernment electromagnetic systems operating within this geographic boundary between $75 \mathrm{MHz}$ and $5 \mathrm{GHz}$ were tabulated. The active files showed 813 government systems and 685 civilian authorizations operational within these boundaries.

Four purposes of this initial environmental assessment, the equipment/ system categories identified in the file retrieval are:

Military Development and Operational Test and Evaluation

- Instrumentation radars - conical scan and monopulse modes.

- Traffic monitor/control radars.

*Dutton, E.J., Precipitation Variability in the U.S.A. for Microwave Terrestrial System Design, OT Report 77-134 (November 1977). 
Table 4.2 Scatter Power Densities - Average Rain Conditions

\begin{tabular}{lccccc}
\hline & \multicolumn{2}{c}{$\begin{array}{c}\text { Average Power Density } \\
\left(\mathrm{mW} / \mathrm{cm}^{2}\right)\end{array}$} & & Field Intensity $(\mathrm{mV} / \mathrm{m})$ \\
\cline { 2 - 3 } Site & $1 \mathrm{hr} / \mathrm{yr}$ & $5 \mathrm{~min} / \mathrm{yr}$ & $1 \mathrm{hr} / \mathrm{yr}$ & $5 \mathrm{~min} / \mathrm{yr}$ \\
\hline $\begin{array}{c}\text { China Lake } \\
\text { Airstrip }\end{array}$ & $5.27 \times 10^{-7}$ & $2.07 \times 10^{-6}$ & 44.6 & 88.3 \\
$\begin{array}{c}\text { Downtown } \\
\text { Barstow }\end{array}$ & $8.30 \times 10^{-7}$ & $3.25 \times 10^{-6}$ & 55.9 & 110.7 \\
$\begin{array}{c}\text { Edwards AFB } \\
\text { Airstrip }\end{array}$ & $1.17 \times 10^{-7}$ & $4.58 \times 10^{-6}$ & 21.0 & 131.4 \\
$\begin{array}{c}\text { Restricted } \\
\text { Area R 2524 }\end{array}$ & $7.69 \times 10^{-7}$ & $3.01 \times 10^{-6}$ & 53.8 & 106.5 \\
$\begin{array}{l}\text { George AFB } \\
\text { Airstrip }\end{array}$ & $5.80 \times 10^{-7}$ & $2.27 \times 10^{-6}$ & 46.8 & 92.5 \\
\hline
\end{tabular}

Military Development and Operational Test and Evaluation (Cont'd)

- Radar transponders.

- Radar signal and functional replicators.

- Wideband monitor receivers with recognition/ decision software scan instantaneous frequency modes.

- Television cameras for target position track.

- Electromagnetic system operational monitors multiple wideband receivers with processing sof tware.

- Range command/control communications nets.

- Range telemetry communications networks.

Industrial Communications

- Utility network command/control and telemetry.

-. Pipeline network command/control and telemetry.

- Water resource telemetry.

- Multiplexed carrier networks - two major service systems.

Transportation Support Systems

- Railroad mobile equipment - yards and enroute complex.

- Air traffic control network.

- Emergency services - mobile, base station, and relay equipment - medical and general emergency applications.

- Railroad "car condition" monitors. 


\section{Public Service Communications}

- State of California backbone network.

- Law enforcement systems - state, county, city - mobile, relay, and base station equipment.

- Forest service units.

- Fire and government emergency systems - county and city operations.

- Common carrier networks - telephone, data, television services - remote area voice links.

Specialized Services

- Space tracking and monitoring facilities (Goldstone area).

- Railroad hump radars.

These system categories are in the frequency range cited for the file retrieval and are susceptible to SPS power densities listed in Table 4.2.

The character of functional degradation induced into particular major equipment categories deployed near the candidate Mojave site is indicated in Table 4.3. Those functional systems include high priority operations that encompass relatively large geographic areas around the periphery of the rectenna site.

The elements of performance degradation cited for the functional systems represent average overall operating modes and geographir. range, For example, instrumentation radar systems detection and tracking performance includes operation over a full hemisphere coverage, and the range of cross section magnitudes for military target vehicles (e.g., tactical fighter and reconnaissance aircraft, target drones). Track score variations include low elevation angle modes where the accuracy degradation and loss of lock probabilities expand by greater margins because of propagation factors.

The communications system degradation cited includes single channel, and frequency and time multiplexed units operated by the military test ranges, the State of California, local county and municipal governments, and resource control and service industries.

The performance degradation is related to operational compromises of the military instrumentation and systems used in operational testing at China Lake, George Air Force Base, Edwards Air Force Base, and the ECHO facility; and the command/control and other communications facilities associated with the resource management operations by utilities and local governments. 
Table 4.3. Induced-Functional-Degradation Summary - Mojave Area

\begin{tabular}{|c|c|}
\hline Function & Characteristic Effects \\
\hline $\begin{array}{l}\text { Instrumentation Radar } \\
\text { (Military Test Ranges) }\end{array}$ & $\begin{array}{l}\text { - Cooperative target acquisition range: }-(8-20 \%) \\
\text { - Skin target acquisition range: }-(13-28 \%) \\
\text { - Cooperative target track error: }+(15-40 \%) \\
\text { - Skin target track error: +(22-65\%) } \\
\text { - Loss of track loop 1ock (skin mode) probability } \\
\text { increase: }+(10-40 \%)\end{array}$ \\
\hline $\begin{array}{l}\text { Command/Control and } \\
\text { Telemetry Communications } \\
\text { (Military Test Ranges) }\end{array}$ & $\begin{array}{l}\text { - Signal acquistion threshold: }+(5-20 \%) \\
\text { - Data error: +(5-28\%) } \\
\text { - Sync loss probability: +(3-25\%) }\end{array}$ \\
\hline $\begin{array}{l}\text { Tactical Signal Identifi- } \\
\text { cation - Analysis Systems }\end{array}$ & $\begin{array}{l}\text { - False alarm probability outside mission zone: } \\
+(3-25 \%) \\
\text { - False alarm probability within mission zone: } \\
+(18-60 \%) \\
\text { - Receiver noise threshold: }+(5-40 \%) \\
\text { Signal processing time: }+(45-115 \%) \\
\text { - Software overload probability increase: } \\
+(2-26 \%)\end{array}$ \\
\hline $\begin{array}{l}\text { Infrared Scanner (Tactical } \\
\text { System) }\end{array}$ & $\begin{array}{l}\text { Video noise threshold: }+(2-26 \%) \\
\text { - Target detection/identification probability: } \\
-(5-33 \%)\end{array}$ \\
\hline $\begin{array}{l}\text { Utility and Pipeline } \\
\text { Command/Control/Telemetry } \\
\text { Communications }\end{array}$ & $\begin{array}{l}\text { - Signal acquistion threshold: }-(5-15 \%) \\
\text { - Data error: }+(10-30 \%) \\
\text { - Link noise: }+(5-20 \%)\end{array}$ \\
\hline Image Intensifiers & $\begin{array}{l}\text { Video noise level: }+(10-45 \%) \\
\text { - Standard target detection/identification } \\
\text { range: }-(5-30 \%) \\
\text { - Multiple target spatial resolution: }-(2-60 \%)\end{array}$ \\
\hline $\begin{array}{l}\text { Nonfederal Government } \\
\text { Communications }\end{array}$ & $\begin{array}{l}\text { - Channel noise: }+(5-15 \%) \\
\text { - Data error: }+(8-35 \%)\end{array}$ \\
\hline
\end{tabular}

The derivation of the performance impact data and support relationships are discussed in the detailed technical report for this initial rectenna site analysis.* This report will demonstrate the effects upon national resources and economics of the SPS-induced performance degradation, and the specific effects upon the major military operations in the Mojave area.' The opera-

*Electromagnetic Compatibility Analysis of the Candidate Mojave SPS Rectenna, Institute for Telecommunications Sciences, to be published. 
tional compromises and the specific areas of functional degradation will be used as the basis for subsequent recommendations in equipment and system operations to assure an acceptable. level of performance.

For this Mojave site and others having a similar operational military/ civil system ratio, modification recommendations will emphasize the civilian area: Support equipment (e.g., radar, telemetry, TV, etc.) can be modified for operation within a range of 40-50 km from the rectenna site, assuming no media-induced instabilities in the SPS array control. Military operational electromagnetic systems cannot be modified because of the unacceptable probability of operational compromise; system performance or procedures in the test and evaluation exercises would have either little or a deceptive relation to combat operations.

\subsubsection{Conclusions and Recommendations}

The preliminary assessment of SPS microwave emissions on "victim" systems as given here demonstrates the operational degradation that would occur to electronic systems in the SPS-generated environment within approximately $100 \mathrm{~km}$ of the rectenna site. The Mojave site evaluation shows a wide range of performance degradation, particularly in those systems operated by the military. The basic functional and operational impacts of SPS are of such magnitude that in many instances they represent unacceptable or impossible compromises and biases to proper test and evaluation exercises performed by the involved facilities.

The evaluation of the Mojave candidate rectenna site provided impact data to NASA and was used in establishing site selection and evaluation criteria, and allowed a limited exercise of the data retrieval and analysis procedures required for the electromagnetic compatibility analysis of all candidate rectenna sites in the continental U.S. This Mojave site originally considered by NASA allowed a reasonable rectenna isolation from areas of even modest population density, but presents serious interference impacts upon surface and aircraft electronic systems. At this site, military operations represent the majority of the interference problems; the degraded systems being integral components of complex development and operational test and evaluation programs. These military programs require the degree of isolation afforded by the Mojave region. 
Based on the probable operational system degradation near the Mojave site and the inability to establish mitigating strategies without an unacceptable probability of compromising system operation, a second site north and east of the original site was proposed by the Institute for Telecommunication Sciences.* A cursory look at the "victim" systems surrounding the new site indicates different functional classes that lend themselves to mitigating strategies. Most of this equipment could be modified to produce compatability in the SPS-generated environment.

The functional degradation of military, nondefense government, and commercial systems in the Mojave area is basically characteristic of the effects that will be encountered in other areas in the continental U.S. Operational implications and therefore the associated economic impact will vary significantly because of the differing organizations and systems supported by the degraded equipment. Operational-functional relationships will exhibit differing sensitivities.

The Mojave area lends itself well to rectenna resiting because of the large expanse of open, flat terrain. The development of new sites in most geographic areas would not be as simple -- in fact, might be impossible -- due to population density, terrain features, victim system density, etc.

Generally, the Northern and Eastern U.S. will have a smaller militarynondefense equipment concentration in the rectenna areas than the original Mojave site reviewed. However, these regions will also have major transportation and commercial communications facilities. Because of the population and business densities, the total number of affected systems in the various operational categories will be larger.

A valid demonstration of rectenna site electromagnetic compatibility analys is and impact evaluation has been developed. This analysis is fundamental in making site selections and will help determine system performance impacts and develop mitigating strategies for victim systems. It is recommended that several site evaluations in various geographical locations, particularly in the Northern and Eastern U.S., be carried out to establish a data base to be used in setting the site selection criteria and geogra-

*Electromagnetic Compatibility Analysis of the Candidate Mojave SPS Rectenna, Inslilute for Telecommunications Sciences, to be published. 
phically-oriented mitigating strategies. A follow-on program should be designed to develop mitigating strategies and techniques for electronic equipment and systems operating in an SPS environment.

\subsection{IONOSPHERIC HEATING AND VEHICLE EFFLUENT EFFECTS}

The amount of power to be transmitted from the geostationary orbit of the satellite power system to the earth's surface may be large enough to substantially heat the earth's ionosphere. This heating could modify the natural ionospheric structure, which could lead in turn to significant changes in the performance of telecommunications systems that rely upon the propagation of electromagnetic energy within and through the ionosphere.

Figure 4.4 illustrates potential SPS impacts on the ionosphere and telecommunication systems. The SPS power beam could generate electron density

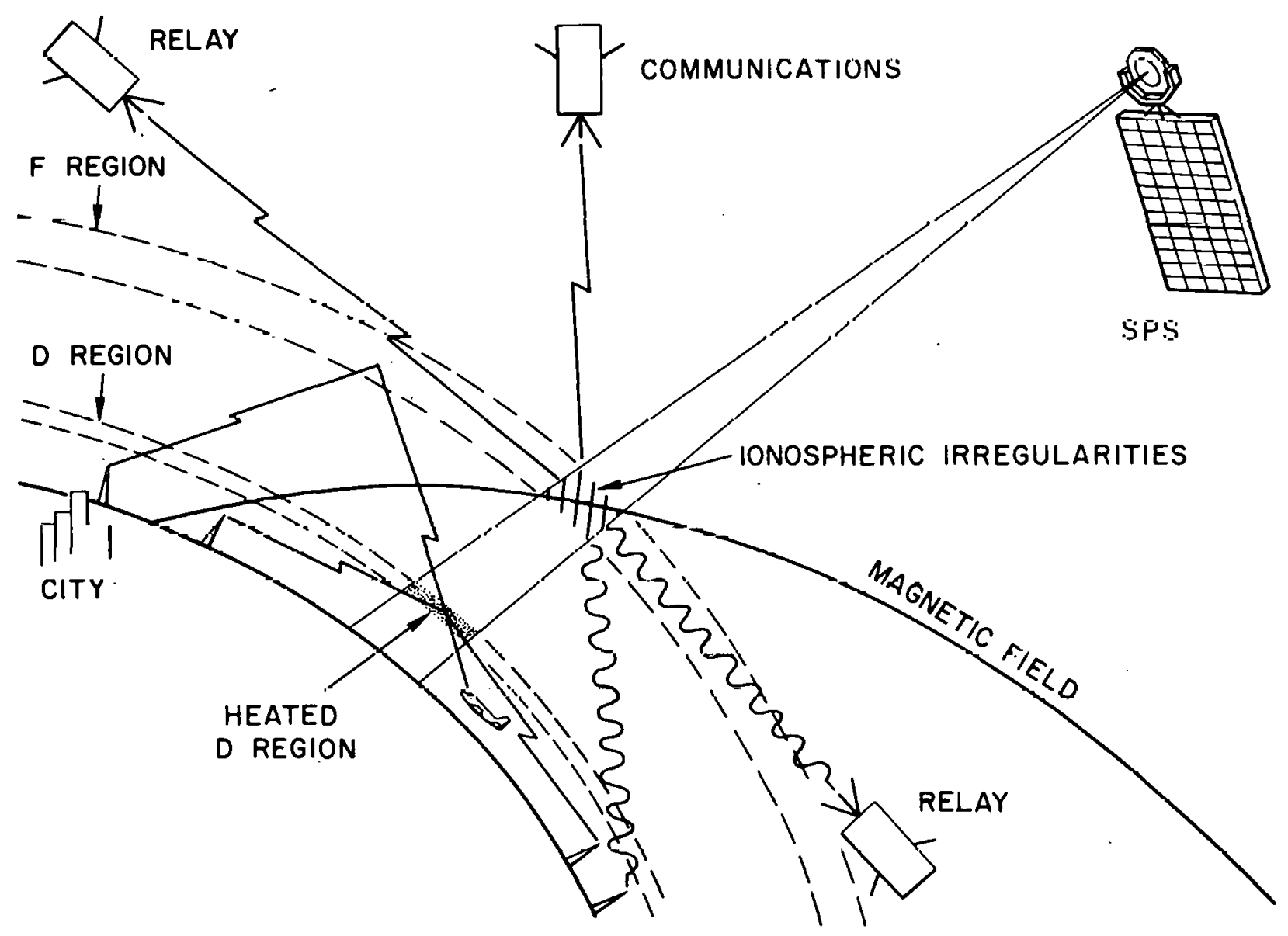

Fig. 4.4. Effect of SPS Microwave Transmission on the Ionosphere and Telecommunication Systems 
irregularities in the $F$ region of the ionosphere and could cause large amounts of excess heat to be deposited in the $D$ region. The $F$ region irregularities could induce fading or scintillation on satellite-to-ground communications links. Radio waves propagated between various locations on the earth that pass through, or are reflected by, the heated $D$ region will suffer increased attenuation that could result in the signal strength falling below the ambient noise level or the receiver sensitivity.

The number and the frequency of launches of heavy lift launch vehicles needed to establish and maintain the SPS also may lead to significant changes in the ionosphere and magnetosphere. These changes could result from the exhaust from the launch vehicle engines and it is expected that they would be characterized by large areas of depleted electron concentration in the upper (250-450 km) regions of the ionosphere. These changes could lead as well to profound changes in the performance of telecommunications systems whose electromagnetic energy is propagated through the ionosphere.

Considerable knowledge-exists concerning the effects on the ionosphere of large amounts of heat propagated into it from below. Most of the knowledge results from ionospheric heating studies in the early 1970s sponsored by the Department of Defense Advanced Research Projects Agency. The experimental efforts and supporting theoretical studies were directed toward understanding the heating of the ionosphere using high frequency electromagnetic waves reflected from the ionosphere. The heating in this case results from parametric interactions between the ionosphere and the heating radio wave. In the case of heating by the SPS power beam, the radio wave will not be reflected by the ionosphere but will pass through. In this case, the heating is due to an ohmic-type interaction between the ionosphere and the SPS power beam.

Information regarding launch effluent effects on ionospheric characteristics is primarily limited to that observed (and consequently explained theoretically) during the launch of skylab. The data pertaining to launch effluent effects preclude inferring detailed temporal and spatial changes in ionospheric structure resulting from the launch activity.

Experimental results are just becoming available on the effects on the ionosphere of high-powered radio waves whose frequencies exceed the F-region critical frequency, giving rise to underdense heating. 'Further theoretical and experimental studies are needed to assess the impact of 
underdense heating on the ionosphere, to determine the resultant impact on telecommunications systems, and to ascertain if the SPS pilot beam will be adversely affected by the SPS power beam.

In order to significantly advance our understanding of, and hence our ability to predict, the SPS impact on the ionosphere, these studies will have to rely on simulation of SPS effects using ionospheric heating facilities that operate at frequencies significantly below the SPS frequency. These facilities in fact rely on the heating of the ionosphere by high frequency radio waves. The results of such simulations can be extrapolated to the SPS frequency if the heating is truly ohmic and the appropriate theoretical studies are undertaken to permit a valid scaling of the results.

Depletion and stabilization model studies coupled with vebicle launch parameter and communicationo link meagurements should be cousdiualed su as to demonstrate the typical range of frequencies and geographic extent of services affected by launch vehicle effluents. Ionospheric characteristics for input to communication prediction models should also be provided through the physical model and measurement ettorts. 